\title{
Determining Water Content in an Active Landfill with the Aid of GPR
}

\author{
April Yochim 1,2 , Richard G. Zytner ${ }^{3 b}$, Edward McBean 4 , Anthony L. Endres ${ }^{5}$ \\ ${ }^{1}$ Grad Student, School of Engineering, University of Guelph, Guelph, ON N1G 2W1 \\ 3Professor (rzytner@uoguelph.ca) \\ School of Engineering, University of Guelph, Guelph, ON N1G 2W1 \\ ${ }^{4}$ Professor (emcbean@uoguelph.ca) \\ School of Engineering, University of Guelph, Guelph, ON N1G 2W1 \\ ${ }^{5}$ Associate Professor (alendres@sciborg.uwaterloo.ca) \\ Dept. of Earth \& Environmental Sciences, University of Waterloo, Waterloo, ON N2L 3G1 \\ ${ }^{\mathrm{b}}$ corresponding author: 1-519-824-4120
}

This is an Accepted Manuscript of an article published by Elsevier in Waste Management, accepted on 22 May 2013, published on-line http://dx.doi.org/10.1016/j.wasman.2013.05.020.

\section{Open Access}

The Atrium (U of Guelph) - http://hdl.handle.net/10214/14127

\footnotetext{
${ }^{1}$ present address, Environmental Project Engineer (ayochim@regionofwaterloo.ca), Region of Waterloo Waste Management Division, 925 Erb Street West, Waterloo, Ontario N2J $3 Z 4$
} 


\title{
Determining Water Content in an Active Landfill with the Aid of GPR
}

\author{
April Yochim 1,2 , Richard G. Zytner ${ }^{3 b}$, Edward McBean ${ }^{4}$, Anthony L. Endres ${ }^{5}$ \\ ${ }^{1}$ Grad Student, School of Engineering, University of Guelph, Guelph, ON N1G 2W1 \\ 3Professor (rzytner@uoguelph.ca) \\ School of Engineering, University of Guelph, Guelph, ON N1G 2W1 \\ ${ }^{4}$ Professor (emcbean@uoguelph.ca) \\ School of Engineering, University of Guelph, Guelph, ON N1G 2W1 \\ ${ }^{5}$ Associate Professor (alendres@sciborg.uwaterloo.ca) \\ Dept. of Earth \& Environmental Sciences, University of Waterloo, Waterloo, ON N2L 3G1 \\ ${ }^{\mathrm{b}}$ corresponding author: 1-519-824-4120
}

\section{ABSTRACT}

Landfill gas (LFG) continues to receive a great deal of attention due its potential for negative environmental impacts while also representing a green energy source. However, predicting the quantity of LFG generated at a given landfill is difficult due to the heterogeneities present in waste, and the lack of accurate in-situ waste parameters like water content. Measuring water content in-situ is challenging within an active landfill, so ground penetrating radar (GPR) is evaluated as a tool for measuring in-situ water content. Due to the large degree of subsurface heterogeneity and the electrically conductive clay cap covering landfills, both of which affect the transmission of the electromagnetic pulses, there is much scepticism concerning the use of GPR to quantify in-situ water content within a municipal landfill.

The utility of GPR was evaluated at two municipal landfills. The first landfill was used to develop the measurement protocols, while the second landfill provided a means of confirming these protocols. GPR measurements were initially completed using the surface GPR approach, but the lack of success led to the use of borehole GPR. Both zero offset profiling (ZOP) and multiple offset gathers (MOG) modes were tried, with the results indicating that borehole GPR using the ZOP mode is the most simple and efficient method to measure in-situ water content. Effectiveness decreased with an increase in separation distance between boreholes, with a higher water content further decreasing the effective separation distance. However, the increased water content did appear to increase in accuracy of the GPR measurements. For a separation distance of $2 \mathrm{~m}$ at the two landfills, the difference in GPR and lab measured water contents were reasonable

\footnotetext{
${ }^{1}$ present address, Environmental Project Engineer (ayochim@regionofwaterloo.ca), Region of Waterloo Waste Management Division, 925 Erb Street West, Waterloo, Ontario N2J $3 Z 4$
} 
at $33.9 \%$ for the drier landfill and $18.1 \%$ for the wetter landfill. Infiltration experiments also showed the potential to measure small increases in water content.

Key words: landfills, methane, ground penetrating radar, ZOP, MOG, water content

\section{$1.0 \quad$ INTRODUCTION}

Sanitary landfills are engineered facilities designed for the disposal of solid wastes with minimum impact on the health of the public and the environment (Tchobanoglous et al.,1993). With naturally occurring biodegradation of the waste, landfill gas (LFG) is produced, which is primarily composed of methane and carbon dioxide in relatively equal amounts (55\% methane, $45 \%$ carbon dioxide and $1 \%$ trace constituents (Atcha and Van Son, 2002). Unfortunately, both methane and carbon dioxide are greenhouse gases, with methane having 23 times greater global warming potential when compared to carbon dioxide (Atcha and Van Son, 2002). Overall, landfills are the largest source of anthropogenic methane, representing approximately $34 \%$ of all methane emissions in the United States (USEPA, 2006).

On the other hand, LFG may be harnessed as a significant source of renewable energy (USEPA, 2008). Hence, the collection of LFG not only reduces environmental impacts, but could provide a tangible economic benefit (USEPA, 1996). According to Environment Canada (2002), the amount of methane produced by Canadian landfill sites can supply the energy needs of more than 600000 homes per year.

Heterogeneity within a landfill makes it extremely difficult to estimate methane generation rates. Placement of the waste in a typical landfill creates major heterogeneities in terms of water content, refuse density, particle size and density, porosity, permeability, temperature, waste age and composition, oxidation reduction potential, alkalinity and $\mathrm{pH}$ (Garg et al., 2006). Both daily and intermediate covers in a landfill create waste cells that differ greatly within an individual cell and between cells (Tchobanoglous, 1993). In addition these complexities differ greatly from site to site.

Various models have been developed to improve prediction capabilities. Garg (2007) developed a 1D numerical model for gas generation and transport in a landfill. The model incorporates a number of heterogeneities previously described; however, is limited by the nature of 1-D modeling. Wang et al. (2010) extended the work of Zhao (2007) on a 3-D soil vapour model to develop a 3-D model for gas generation 
and transport within a landfill. However, the 3-D model is limited by parameter assignment uncertainties including in situ water content.

Water content is an important parameter that greatly influences landfill gas generation rates. Water in a landfill promotes bacterial growth as well as provides the means of bacteria and nutrient movement within the refuse. An optimal water content of waste exists such that gas production is highly encouraged (Tchobanoglous, 1993). Water content in a landfill is extremely variable and depends on such parameters as rainfall, type of capping, waste type, site management etc., and varies both spatially and temporally. Therefore, in order to accurately model methane production within a landfill in 3-D, water content must be specified, taking into consideration spatial and temporal variability. Therefore, a quick and easy method of identifying water content is vital to better predict landfill gas generation. Imhoff et al. (2007) reviews several different techniques for measuring moisture content of landfilled waste.

Recent studies have evaluated the use of time domain reflectometry (Li and Zeiss, 2001, Staub et al., 2010) and transmission methods (Masbruch and Ferre, 2003) for monitoring water content in municipal waste; both of these methods are based on the transmission of an electromagnetic (EM) wave. While this work clearly demonstrates the value of EM wave methods for monitoring water content in municipal waste, these probes are invasive and their small sampling volumes (i.e., $\mathrm{cm}^{3}$ ) limit these techniques to point measurements which would have to be extrapolated over large areas. A non-invasive geophysical method based on the same principles of EM wave propagation is ground penetrating radar (GPR). Because GPR measures larger volumes of soil (i.e., on the order of $\mathrm{dm}^{3}$ to $\mathrm{m}^{3}$ ) it is much better suited for field scale applications than standard point measurement technique. Many studies have proven that GPR has the ability to not only effectively image the subsurface, but also to quantify subsurface parameters (Knight, 2001). The ability of GPR to characterize water content, and changes in water content outside of the landfill environment has been extensively researched using both surface and borehole (BH) GPR techniques (Huisman et al., 2003).

The majority of studies that have utilized GPR in a landfill setting have investigated delineating landfill borders and locating miscellaneous buried waste, (Lanz et al., 1998; Smith, 1999; De laco et al., 2000; Splajt, 2003), identify landfill leachate plumes (Gilson et al., 1996; Faust, 2004; Porsani et al., 2004), and map thickness and continuity of landfill capping (Bulford, 2002; Guyonnet et al., 2003; Piggott, 2004). 
However, there has been extremely limited success using surface GPR to quantifying subsurface parameters within the refuse in a landfill due to the highly conductive nature of landfill waste and covers

Recently, effort has been made to evaluate the ability of cross-borehole GPR to measure water content within a landfill. Glancy (2009) tested the effectiveness of cross-borehole GPR at a bioreactor landfill. Cross-borehole GPR was conducted between two vertically installed access tubes at a separation distance of $10 \mathrm{~m}$ using $100 \mathrm{MHz}$ antennas. Glancy (2009) reported that no radar signal was recorded at the $10 \mathrm{~m}$ distance. The inability to transmit usable signal over this large borehole separation was attributed to the highly conductive nature of the waste material which severely attenuates EM waves.

In contrast, a study conducted by Cassiani et al. (2008) successfully used borehole GPR to characterize the water content of refuse in an existing landfill. The main purpose of the study was to assess the effectiveness of the cap by characterizing the moisture content profile below the cap during natural rainfall and artificial irrigation. Cassiani et al. (2008) utilized a $100 \mathrm{MHz}$ GPR vertical radar profile (VRP) configuration in landfilled waste as large separations (i.e., tens of meters) between existing BHs on the site made the cross-borehole GPR configuration unfeasible. The success of the borehole GPR survey using a VPR configuration demonstrates that usable transmission of EM waves can be achieved in landfill waste. It is important to note that the landfill investigated by Cassiani et al. (2008) was much shallower than a typical modern landfill in North America.

The objective of this research project was to further assess the capacity of GPR to quantify in-situ subsurface water content in active landfills. Two active landfills were used as test sites. The GPR configurations tested were surface and vertical cross-borehole measurements. For the borehole approach, the zero offset profiling (ZOP) and multiple offset gathers (MOG) modes were tested.

\subsection{SITE DESCRIPTIONS}

Two operating landfills were used to evaluate the performance of surface GPR and vertical crossborehole GPR in heterogeneous landfill environments. The first landfill was used to develop a process, modify and test, while the second landfill was used to confirm the process. Spatial resolution of the GPR configurations was also tested. The Region of Waterloo Landfill (RWL) located in Waterloo, Ontario, was 
the primary study site. The City of Hamilton Glanbrook Landfill (GL) located outside of Binbrook, Ontario was the secondary study site.

\subsection{Region of Waterloo Landfill}

The Region of Waterloo Landfill (RWL) covers an area of approximately 130 hectares with approximately 70 hectares approved for filling. The original landfill area opened in 1972 and was closed in 2002 with expansion areas still operating. Two zones of expansion are located on the northern and southern edges of the site. Landfill gas is collected and used to generate electricity from the landfill gas. The region accepts non hazardous municipal, industrial, commercial and institutional solid waste (Region of Waterloo, 2007).

Areas of investigation at the RWL were located in the northern and southern expansion areas. The southern expansion site is currently an active tipping face with no final capping and therefore providing direct contact with waste, making surface GPR a possible option. The northern expansion area is not currently operating and had a final cover with an average depth ranging between 0.3 to $0.9 \mathrm{~m}$.

In 2005, the MOE approved the trial-use of two different alternative daily covers: a tarp system and a cellulose based, spray-on cover. Both were present at the areas investigated for this research. An additional advantage of the selected sites was the revised landfilling practices in affect. Numerous by-laws and bans restrict the type of waste accepted. As a result, there should be significantly less tires, corrugated cardboard, wooden pallets, electronic waste, hazardous waste, yard waste and a reduced amount of food waste in the areas of investigation compared to the original landfill area. The ban on yard waste and the implementation of food waste composting significantly decreased the volume of organics present in the landfill.

\subsection{Glanbrook Landfill in Hamilton}

The Glanbrook Landfill is approximately 220 hectares (including landfill area and buffer zone). The approved waste footprint is approximately 60 hectares (Balsdon, 2008). The landfill opened in 1980 and is still operating. Landfill gas is collected and used to generate electricity on site. 
GL is approved to accept only domestic, commercial and non-hazardous solid industrial waste. At the location of investigation, only an interim cover was present to a depth of approximately $40 \mathrm{~cm}$. For a few years during landfill construction, woodchips were used as daily cover. This practise likely increased the amount of water that entered the landfill for that period of time. This situation is unlike the RWL where soil higher in clay content was frequently used for daily cover.

\subsection{METHODOLOGY and EXPERIMENTATION}

Estimating water content from GPR data is based on determining the dielectric permittivity $(K)$, of the landfill waste. The dielectric permittivity is calculated through a relationship between velocity of an electromagnetic $(E M)$ wave in a medium $(v)$, and the velocity of an EM wave in a vacuum $(c \sim 0.3 \mathrm{~m} / \mathrm{ns})$ given by

$$
K=\frac{c^{2}}{v^{2}}
$$

Topp et al. (1980) developed an empirical equation to relate the dielectric permittivity of a soil and its volumetric water content $(\theta)$. The Topp et al. relationship is independent of soil type, soil density, soil temperature, and soluble salt content. It can be used to determine water content, from fully saturated to air dry materials within an error of $0.013 \mathrm{~m}^{3} / \mathrm{m}^{3}$ (Topp et al.,1980):

$\theta=-5.3 \times 10^{-2}+2.92 \times 10^{-2} \mathrm{~K}-5.5 \times 10^{-4} \mathrm{~K}^{2}+4.3 \times 10^{-6} \mathrm{~K}^{3}$

A second empirical relationship was developed called the complex refractive index method (CRIM). The CRIM uses a volume averaging relationship that incorporates porosity, volumetric water content, and the dielectric constant of solid matrix, air and water phase (Roth et al. 1990; Chan and Knight 1999). The CRIM relationship can be used when the above properties of the medium are available or can be readily measured and quantified. However, for the purpose of this study this was not the case and therefore the Topp et al. (1980) equation was adopted (Cassiani et al., 2008 and Glancy, 2009). 


\subsection{Phase One: Surface GPR on RWL}

Phase One was conducted at the RWL from September to December, 2008. Various frequencies were tested to determine an appropriate combination of penetration and resolution. Deeper penetration can be achieved with a decrease in transmitter frequency. However, this reduces the resolution (Nuzman and Kinn, 1995). Surface GPR data were collected using a pulseEKKO $100 \mathrm{GPR}$ with $25 \mathrm{MHz}, 50 \mathrm{MHz}$, and $100 \mathrm{MHz}$ antennas and a $400 \mathrm{~V}$ transmitter. Using the $100 \mathrm{MHz}$ antennas, $50 \mathrm{MHz}$ antennas, and 25 $\mathrm{MHz}$ antennas; the antenna separation was set to $1 \mathrm{~m}, 2 \mathrm{~m}$ and $4 \mathrm{~m}$, respectively, and the antenna step size was $0.10 \mathrm{~m}, 0.25 \mathrm{~m}$, and $0.50 \mathrm{~m}$, respectively (Sensors \& Software, 2001, 2008). All data presented in this paper were collected using 64 stacks to increase the signal to noise ratio.

Three areas of the landfill were tested. Success was only possible at the tipping face due to the limited thickness of clay cover. The other locations were found to be unsuccessful due to the thickness of the clay final cap, which prevented the signal from penetrating the cap and entering the waste. Accordingly, surface scan field trials were undertaken on two occasions; November $5^{\text {th }}$ using $100 \mathrm{MHz}$ antennas, and December $12^{\text {th }}$ using $50 \mathrm{MHz}$ and $25 \mathrm{MHz}$ antennas. At both times, two survey methods were performed: the common offset method (CO) and the common midpoint method (CMP). Additional details of these methods are given in Annan (2007).

\subsection{Phase Two: Cross-borehole GPR on RWL}

Phase Two of the project was completed during a three month period on the northern expansion area of the RWL. During the three months, the maximum distance and required frequency at which crossborehole GPR could be used within the waste was tested. Refuse water content was determined using a gravimetric approach as a function of depth during BH installation to assess GPR readings of water content.

To determine the maximum distance at which GPR was effective, a range of $\mathrm{BH}$ separations were tested. In order to avoid wave interference, a minimum separation distance of $2 \mathrm{~m}$ was required. In addition, to ensure that the signal would not be fully attenuated before it reached the receiving antenna, a maximum $\mathrm{BH}$ separation of $5 \mathrm{~m}$ was assigned. Figure 1 shows the layout of the concentric circle design that was implemented. The circles on Figure 1 denote the separation distance from the access tube labelled 0 and are present for visual purposes only. Access tubes labelled 2, 3, 4 and 5 were separated from access tube 
0 by $2.16 \mathrm{~m}, 2.87 \mathrm{~m}, 3.92 \mathrm{~m}$, and $4.93 \mathrm{~m}$ respectively. In total, five access tubes made of SCH 80 PVC pipe were installed. All tubes had an approximate depth of $6.7 \mathrm{~m}$, with $0.61 \mathrm{~m}$ of pipe through the clay cap and $6.1 \mathrm{~m}$ penetration into the waste.

Refuse samples were collected from BHs 0,3 and 5 during drilling for comparison with the GPR derived water content. Bulk samples of auger cuttings were collected at approximately $75 \mathrm{~cm}$ intervals. In total, nine samples were taken per $\mathrm{BH}$. The samples were transported back to the laboratory on ice and stored in a refrigerator at $4^{\circ} \mathrm{C}$ until analysis. It is important to note that the shallowest samples were comprised mostly of final and intermediate cover (mostly clay material). Three split spoon samples were taken in access tube 5, at depths of 2.5, 5.0 and $12.5 \mathrm{~m}$ and used to determine refuse bulk density. Bulk density was used to convert gravimetric water content to volumetric water content, which could be compared to in-situ GPR derived volumetric water content. All gravimetric water content measurements were taken as a percentage of as-received mass.

Water content, volatile content, electrical conductivity $(\mathrm{EC})$ and $\mathrm{pH}$ were analysed in the laboratory. Attention was restricted to water content, which was determined gravimetrically. This was done through oven drying approximately $50 \mathrm{~g}$ of the original solid waste sample at $70^{\circ} \mathrm{C}$ for $24 \mathrm{~h}$ (Tchobanoglous et al., 1993, Klute, 1986, Reddy et al., 2009, Chang and Davila, 2008).

Vertical cross-borehole GPR data was collected using the pulseEKKO 100 system with $50 \mathrm{MHz}$ and $100 \mathrm{MHz}$ borehole antennas, combined with a $400 \mathrm{~V}$ transmitter. The antenna step size for the $\mathrm{BH}$ GPR surveys was $0.10 \mathrm{~m}$ and $0.20 \mathrm{~m}$ for the $100 \mathrm{MHz}$ and $50 \mathrm{MHz}$ antennas, respectively. Two crossborehole survey modes were used to collect data at the RWL, zero offset profile (ZOP) and multiple offset gather (MOG). Background information on these borehole GPR methods was given in Annan (2007).

The ZOP survey technique was used to gather a one dimensional velocity profile along the length of the BHs. All ZOP data were recorded as the transmitter (in access tube 0) and the receiver (in outer access tubes $2,3,4$ or 5) simultaneously advanced down the BHs in equal step sizes. All radar traces were recorded when both antennae were at identical elevations within their respective BHs. Each radar trace corresponds to an average velocity between the two BHs at a specific elevation. All ZOP surveys were performed two to three times to assess repeatability of the results. Before each ZOP survey, the antennas were calibrated accordingly. To perform calibrations, each antenna was held aboveground in the same 
orientation and antenna separation as they would be in the access tubes, measuring air wave velocity. The velocity of the air wave was later used in data processing as a reference point for calibration (Bulford, 2002).

The MOG survey technique was used to gather a tomographic image of the two dimensional plane between two BHs (Annan, 2007). All MOG data were recorded with the transmitter (in $\mathrm{BH}$ 0) and the receiver (in outer BHs 2, 3, 4, or 5). To record one multiple offset gather, the transmitter was held at a specified elevation and the receiver was advanced down the $\mathrm{BH}$ in equal step sizes as traces were recorded. Upon completion of one gather, the transmitter antenna was advanced down the $\mathrm{BH}$ one step size and the process is repeated. MOG surveys were only performed once. The antennae were recalibrated before each set of MOG surveys for one BH separation.

All BH GPR data were initially processed with PICKER, a data picking software provided by Sensors \& Software (2001) to determine first breaks. The first break is the moment at which the transmitted radar signal first arrives at the receiving antenna (Bulford, 2002). By picking the first break times of the radar trace, the travel time of a wave from the transmitter to the receiver is measured, allowing the EM velocity of the wave to be determined.

PICKER was used to perform automatic first break picking on all data (ZOP and MOG) using the following pick options: boxcar filtering with a filter length of 1 and a pick threshold of either $5 \%$ or $20 \%$ on the negative edge of the first arrival pulse only. The appropriate value of the picking threshold depends upon the quality of the data. Higher quality data could be picked with a lower threshold of $5 \%$ which provides a more accurate determination of the arrival time corresponding to the first break. Lower quality data could only be processed using a $20 \%$ threshold which produced unacceptable error in the first break determination. Therefore, data processed using a $20 \%$ threshold was manually adjusted to coincide with a $5 \%$ threshold pick. A picking threshold adjustment of $8.7 \%$ was directly applied to raw data picked at a $20 \%$ threshold. The picking threshold adjustment was estimated using the highest quality data and calculating a percent difference between first breaks picked using a pick threshold of $5 \%$ and $20 \%$ on the same data. The majority of data that required adjusting were acquired with high $\mathrm{BH}$ separation distances and data acquired with $100 \mathrm{MHz}$ antennas.

A time shift from a $20 \%$ picking threshold to a $5 \%$ picking threshold will be slightly different depending on data quality. Data with poorer data quality was found to be characterized by slightly elongated wavelets, 
which was found to increase the percent difference between first breaks picked using a pick threshold of $5 \%$ and $20 \%$. To account for this, the average time shift value of $8.7 \%$ was calculated using the highest quality data between $\mathrm{BHs} 0$ and 2 and $\mathrm{BHs} 0$ and 3, and was accepted as an insignificant systematic error in the experiment.

Velocity values determined from the ZOP data were converted to water content using Equations (1) and (2) to produce a one dimensional vertical profile of average water content. Analysis of MOG data was performed using GeoTomCG modeling program (Tweeton, 2008). GeoTomGG used velocities extracted by PICKER to produce two dimensional tomographic velocity profiles. Subsequently velocities were converted to water content using Equations (1) and (2). Outliers were removed in GeoTomCG using the Remove Outliers function with a minimum and maximum time cut off of $15 \mathrm{~s}$ and $9000 \mathrm{~s}$ respectively. A graph displaying time versus source-receiver separation was viewed to ensure that these cut off parameters fell outside the range of the regular data. Performing Remove Outliers removed any hidden anomalies such as -100 s). The cleaned-up data was then converted to a two dimensional tomographic velocity profile by running the Standard Inversion setting.

\subsection{Phase Three: Water Infiltration at Region of Waterloo Landfill}

Phase Three of the project was completed during July, 2009 determine if the GPR technique could measure a moving infiltration front. Given the results from Phase Two, only the $50 \mathrm{MHz}$ antennas were used. The ability to measure infiltration was tested between BHs 0 and 2 by installing a $1.5 \mathrm{~m}$ by $1.5 \mathrm{~m}$ trench by $0.6 \mathrm{~m}$ deep (i.e., the depth of the clay cap). Water was applied directly into the excavated area and infiltration was gravity driven. The volume of water added to the system was not to exceed the field capacity of the waste in a landfill, which was estimated at $45 \%$ vol. (McBean et al., 1995; Innovative Waste Consulting Services, 2007). This volume was estimated to be approximately $3 \mathrm{~m}^{3}$ of water. ZOP and MOG data acquisition and processing were similar to that used in Phase Two. Water infiltration was determined by subtracting the initial ZOP (MOG) data from the final ZOP (MOG) data.

\subsection{Phase Four: GPR Analysis at Glanbrook Landfill}


Phase Four was conducted on July 30, 2009. GPR tests at the GL were conducted to see if the success at the RWL could be repeated at a second landfill. GPR on the GL also allowed the opportunity for comparison of the results from different waste streams. The procedures followed were the same as at the RWL.

At the GL, only three access tubes were installed. Two to a depth of $6.7 \mathrm{~m}$, and one to a depth of 4.9 $\mathrm{m}$ as a result of refuse composition (the drill could not penetrate the waste any further). $\mathrm{BH}$ layout was similar to that at the RWL (see Figure 1), however only BHs 0, 2, and 3 were installed creating a triangular pattern. $\mathrm{BH} 0$ served as the center reference and $\mathrm{BHs} 2$ and 3 were separated from $\mathrm{BH} 0$ by $2.12 \mathrm{~m}$ and $3.07 \mathrm{~m}$ respectively. An additional $\mathrm{BH}$ separation distance was measured utilizing $\mathrm{BHs} 2$ and 3 with a separation distance of $4.0 \mathrm{~m}$. During Phase Two, it was concluded that a separation distance of $5 \mathrm{~m}$ did not provide sufficient signal quality to be used in the GL testing.

Data acquisition and processing was performed in the same manner as the data obtained from RWL to ensure comparable results. Gravimetric water content sampling and analytical methods used at the GL were performed in the same manner as at the RWL except only one $\mathrm{BH}(\mathrm{BH} 0)$ was physically sampled. Similarly, split spoon samples were taken to determine bulk density of refuse. At the GL, two split spoon samples were taken in $\mathrm{BH} 0$, at depths of 4.5 and $6.7 \mathrm{~m}$.

\subsection{RESULTS and DISCUSSION}

\subsection{Surface GPR Surveys}

Surface GPR CMP surveys on the tipping face at RWL indicated that no useful data could be obtained to determine signal velocity within the refuse; hence, water content could not be determined. The only signal that was reasonably identifiable was the direct air wave. The 100, 50 and $25 \mathrm{MHz}$ scans were all unsuccessful, in that all frequencies produced data with no usable direct ground wave or reflected waves. The thin clay daily cover attenuated most of the signal and the refuse attenuated or scattered the remaining signal, effectively reducing signal penetration to zero.

The CMP data were analyzed using velocity processing software, EKKO_View Delux by Sensors \& Software (2001), to determine the apparent velocity of any reflected events present. The $25 \mathrm{MHz}$ analysis indicated a very weak reflection event at an apparent velocity between 0.05 and $0.09 \mathrm{~m} / \mathrm{ns}$ at $500 \mathrm{~ns}$. This 
value is an acceptable velocity value for the refuse given the vertical cross-borehole GPR results discussed in Section 4.2. However, the inherent uncertainty of this result precludes any confidence in the obtained water content.

Based on the surface GPR results, it is currently not feasible to use surface GPR surveys to measure water content in a landfill setting. The reasons include 1) low frequency antennas, required for deeper penetration, are upwards of $2.5 \mathrm{~m}$ in length and very cumbersome, making efficient data collection impossible, 2) the tip face is not a practical location to continually collect data because it is continually changing, 3) two way travel time that is required of surface GPR increases the amount of signal strength needed to transmit reflection events at the receiving antenna.

\subsection{Vertical Cross-Borehole GPR Surveys}

\subsubsection{Data Quality}

Monitoring GPR data quality during the study was accomplished by evaluating the repeatability of the data. To perform this check, every $50 \mathrm{MHz}$ ZOP survey was taken in duplicate or triplicate. The correlation coefficient calculated for each ZOP pair was used to evaluate the duplicated data for variability between measurements (Table 1). Analysis of the correlation coefficients in Table 1 shows that repeatability is high for $\mathrm{BH}$ separation of approximately $2 \mathrm{~m}$. The closer the correlation coefficient is to 1 , the more repeatable the data as the duplicated ZOP measurements are highly correlated. Note, that on June $4^{\text {th }}$ the measurements between $\mathrm{BHs} 0$ and 2, $\mathrm{Z3}$ had lower repeatability than any other. As $\mathrm{BH}$ separation increased, the frequency of inaccurate picks (outliers) on the last two traces (i.e., the deepest antenna location) increased as seen in Table 1 notes. This may suggest something about local environment at the bottom of the borehole. However, by not including the outliers in the correlation coefficient calculation, repeatability remained high. It is important to note that only the last one or two traces had a higher frequency of outliers.

In addition, data quality was evaluated by calculating time shift between ZOP pairs (i.e., data sets), as seen in Table 1. The values given in Table 1 are the $y$-intercepts of the linear relationship between the first arrival times when first arrival times for each ZOP pair are plotted against each other. The low value of the $y$-intercepts indicates that there is no systematic shift between data sets. 


\subsubsection{ZOP Data}

The vertical cross-borehole ZOP surveys using the $50 \mathrm{MHz}$ antenna for the four borehole separation distances are shown in Figure 2; the automatic first break picks using the 5\% threshold level are indicated in each panel. For borehole separations up to approximately $3 \mathrm{~m}$ (Figures $2 \mathrm{a} \& 2 \mathrm{~b}$ ), these results clearly show that data quality is good and velocity determination within the refuse is possible. For the larger borehole separations (Figure $2 c \& 2 d$ ), it can be seen that the signal to noise ratio deteriorates and the radar pulse appears to be distorted and elongated. As can be seen by the quality of the automatic first break picks, it becomes progressively more difficult to obtain accurate travel time measurements for velocity estimates. At $5 \mathrm{~m}$ separation (Figure 2d), it is essentially not possible to determine water content with the ZOP data. In addition, it was found that data quality obtained with the $100 \mathrm{MHz}$ antennas was not sufficient to determine accurate first breaks at any of the four borehole separation.

Table 2 displays the average laboratory analyzed water content and the average GPR analyzed water content (pre-infiltration water content taken on multiple dates throughout June and July averaged per borehole separation). Table 2 also displays the percent difference relative to laboratory derived water content calculated between the laboratory derived water content and the GPR derived water content to compare GPR data against a known method of water content measurement. Percent difference is calculated by dividing the difference between the GPR data and the laboratory data by the laboratory data value. Also displayed in Table 2 are the absolute differences between the laboratory analyzed water content and the GPR analyzed water content. Please note, laboratory derived water content was determined gravimetrically and converted to volumetric water content by using refuse bulk density.

The laboratory determined water content of the sampled refuse represent highly localized information from the immediate vicinity of the $\mathrm{BH}$. In contrast, GPR estimate represents the average water content over a much larger volume of refuse between two BHs. While laboratory derived water content cannot be directly correlated to the GPR estimates, they do provide a good qualitative comparison. Comparisons were subsequently chosen based on locations of $\mathrm{BHs}$ and the general area that is represented by each $\mathrm{BH}$. As a result Laboratory derived data at $\mathrm{BHs} 0,3$, and 5 were compared with GPR derived data at $\mathrm{BH}$ separations of approximately 2,3 and $4 \mathrm{~m}$, respectively. In addition, a comparison of the GPR 
measurements to the average laboratory derived water content from all boreholes was made. Note all water content values are volumetric based as a percent of in-situ volume. Upon inspecting the values in Table 2, the relative closeness in water content values suggests that these values are comparable in the sense of "orders of magnitude" and supports the use of GPR to measure water content in-situ, providing important data for modeling calculations.

Figures 3,4 and 5 show that the vertical water content profiles based on the laboratory derived water content and GPR ZOP surveys for the various $\mathrm{BH}$ separation distances. It can be observed that in all cases that the GPR-derived profiles show the same vertical pattern of water content variation as the laboratory results. This correlation is strong evidence that borehole GPR is capable of providing water content information in the landfill environment. However, it can also be seen that the laboratory derived profiles are consistently shifted to higher water content levels relative to the GPR derived profiles. While we have noted there are potential differences due to sampling volume effects, the consistent displacement of these profiles indicates that a better relationship between dielectric properties and water content is required for refuse material.

Assuming that no natural changes in water content occurred in the capped landfill over a approximately 1 month period, the average absolute difference in water content between ZOP scans can be used to describe experimental error. Therefore the experimental error between BHs 0 and 2 is $+/-0.00523 \mathrm{~m}^{3} / \mathrm{m}^{3}$, between BHs 0 and 3 is $+/-0.00763 \mathrm{~m}^{3} / \mathrm{m}^{3}$ and between BHs 0 and 4 is $+/-0.0111 \mathrm{~m}^{3} / \mathrm{m}^{3}$. These experimental error values are close to the modest expected experimental error of $+/-0.01 \mathrm{~m}^{3} / \mathrm{m}^{3}$ as identified by Parkin et al. (2000). As expected, as the BH separation increased, so did the experimental error due to the decrease in data quality.

\subsubsection{MOG Data}

Due the nature of the survey geometry inherent to the MOG borehole technique, issues concerning the effects of transmitter-receiver separation distance on GPR signal quality become more important. Because the receiver antenna is moved along the borehole length; the transmitter-receiver separation distance varies and is generally greater than the nominal $\mathrm{BH}$ separation. For example, at a separation distance of $2.16 \mathrm{~m}$, the separation between the transmitter and receiver antennas can reach a maximum 
value of $6.50 \mathrm{~m}$. Therefore, only MOG data collected between BHs 0 and 2 possesses adequate quality for analysis. For BH pairs beyond this separation distance, the GPR had trouble getting reliable data. As a result, the MOG data was processed using a $20 \%$ picking threshold and corrected using the $8.7 \%$ time shift determined through analysis.

Figure 6 gives the raw vertical cross-borehole MOG survey using the $50 \mathrm{MHz}$ antenna. The automatic first break picks using the $20 \%$ threshold level are indicated in each panel. For borehole separations up to approximately $2 \mathrm{~m}$ (Figure 6a), these results clearly show that data quality is good and velocity determination within the refuse is possible. For the larger borehole separations (Figures $6 b, 6 c$ and $6 \mathrm{~d}$ ), it can be seen that the signal to noise ratio deteriorates and the radar pulse appears to be distorted and elongated. As can be seen by the quality of the automatic first break picks, it becomes progressively more difficult to obtain accurate travel time measurements for velocity estimates. At $3 \mathrm{~m}$ separation and greater (Figures 6b, 6c and 6d), it is essentially not possible to determine water content with the MOG data. In addition, it was found that data quality obtained with the $100 \mathrm{MHz}$ antennas was not sufficient to determine accurate first breaks at any of the four borehole separation.

Figure 7 shows the two dimensional image of the water content between $\mathrm{BH} 0$ and 2 obtained from the MOG data. Given the differences in the nature of the MOG and ZOP surveys, care must be exercised when comparing the results from these surveys. However, it is apparent that the pattern of water content distribution imaged by the MOG survey is consistent with the ZOP results. In particular, the patterns of water content minima and maxima in the ZOP data can be identified in the MOG data. This is especially noted at the extremes located at an approximate depth of $4.5 \mathrm{~m}$ and $1.5 \mathrm{~m}$.

\subsection{Water Infiltration}

In an attempt to examine the response of the vertical cross-borehole GPR to temporal variations in water content, an infiltration experiment was performed. Based on the success of the cross-borehole analysis between BHs 0 and 2, it was decided that the highest chance for success was to monitor water content changes from water infiltration in this zone.

A total volume of approximately $640 \mathrm{~L}$ of water was gravity-accepted by the refuse during our infiltration experiment. This amount is considerably less than the conservatively estimated $3000 \mathrm{~L}$ needed 
to reach field capacity of the refuse volume. The infiltration period ran from July $6^{\text {th }}$ to July $27^{\text {th }}, 2010$. The water infiltration rate declined from a maximum of $9.4 \mathrm{~L} / \mathrm{h}$ during the first days of experiment to a minimum of $0.60 \mathrm{~L} / \mathrm{h}$ close to its end. The poor infiltration was attributed to the inability of the compacted refuse to accept water.

\subsubsection{Data Quality}

Monitoring data quality during the study was evaluated by performing ZOP surveys two or three times to determine the repeatability of the results. The correlation coefficient calculated for each ZOP pair was used to evaluate the data for variability between measurements (Table 3). Analysis of the correlation coefficients shows that in general high reproducibility was obtained during water infiltration. In addition, data quality was evaluated by calculating time shift between ZOP pairs (i.e., data sets), as seen in Table 3 . The values given in Table 3 are the $y$-intercepts of the linear relationship between the first arrival times when first arrival times for each ZOP pair are plotted against each other. The low value of the $y$-intercepts indicates that there was no systematic shift between data sets.

Due to time constraints, a single MOG survey was performed on each date. Investigating the MOG survey results show that a large difference in the time zero set shifted the data, producing inaccurate velocity measurements. Therefore time zero for each MOG survey was investigated to ensure accurate comparability. Any MOG data set that had anomalies in the time zero set were therefore not used in analysis.

Spatial positioning of the ZOP data is relatively straight forward and highly dependent upon the size of the Fresnel zone (discussed in Section 4.3.3). The results show that the data is fairly reproducible with high correlation coefficients. Ray path density and viewing angle is continuous for all traces. Therefore confidence in consistent and relatively accurate spatial positioning is high, and does not change at different locations in the various BHs.

However, spatial positioning in MOG data is much more complex. The nature of the MOG surveying technique creates low density ray coverage in the top, bottom and sides of the surveyed area. Data in these areas are suspect and must be interpreted with caution. High density ray coverage is found in the central area of the survey. In this area, data is much more accurate with high resolution and accurate spatial 
positioning. Due to the nature of this study and poor water infiltration, accurate and consistent spatial positioning in the first few meters of the scan is very important.

\subsubsection{ZOP Data}

GPR scans can only record an event when the change in subsurface material or property has the ability to change the travel time (i.e., velocity) of the EM wave significantly enough to be detected by the GPR equipment. The ability of a subsurface material or property to change EM travel time is dependent on the size of the element and contrast in dielectric constant between the element and the surrounding environment (Bulford, 2002).

Determination of the Fresnel zone is important when identifying the detection limit of cross-borehole GPR during water infiltration. It is thought that objects or properties that are as small as half of the maximum diameter can affect the EM wave sufficiently enough to be detected (Williamson, 1991). Therefore, the Fresnel zone was used as an estimate of the diameter of the planer area perpendicular to the BHs that would have to be affected by water infiltration in order to be detected (Bulford, 2002, and Piggot, 2004). With respect to BHs 0 and 2 at a separation distance of $2.16 \mathrm{~m}$, the diameter of the Fresnel Zone was calculated to be $2.17 \mathrm{~m}$. This gave a $1 / 2$ Fresnel zone dimension of $1.08 \mathrm{~m}$. Therefore, during the infiltration experiment, a planer area with a diameter of $\sim 1.08 \mathrm{~m}$ perpendicular to the ray path would have to be affected by water infiltration for the EM waves to be detected by the GPR method (Bulford, 2002).

Parkin et al. (2000) reported an experimental error of $+/-0.01 \mathrm{~m}^{3} / \mathrm{m}^{3}$ using similar experimental design. It was therefore assumed that the change in water content had to exceed $+/-0.01 \mathrm{~m}^{3} / \mathrm{m}^{3}$ in order for it not to be considered an artefact of experimental error. Converting this percentage to a detectable volume of water gave $45 \mathrm{~L}$. To account for handling and volatilization losses, a volume of approximately $640 \mathrm{~L}$ was added to the trench during the infiltration experiment. Assuming that only one third of the water placed in the trench traveled vertically into the waste, about $215 \mathrm{~L}$ of water entered the GPR sampling volume. This is more than sufficient water in the sampling to trigger detection.

Another way to assess the detection limit would be to look at the estimated volume of water that entered the waste during infiltration and calculate the water content change that would have resultantly 
occurred, according to the assumed waste porosity. This water content change would then be compared to the experimental error to see if the change in water content was real or experimental error.

The first method was chosen for analysis as the heterogeneity of the waste could possibly create preferential flow pathways. Calculating the change in water content using the second method could therefore generate changes in water content values that differ from the actual changes in water content. Doing so would create unnecessary confusion during interpretation.

The dielectric constant of a material controls the velocity of EM waves (Deignan, 1991). Intuitively, a greater contrast in conditions increases the chance of detection. Little study has been preformed to identify volume of water needed to change soil water content sufficiently enough to change dielectric constant, ensuring detection. Therefore, it is difficult to determine if a given volume of water that will increase water content by more than $1.0 \%$ will also create a large enough contrast for determination of the dielectric constant. Intuitively, if the initial water content is low, then the addition of water would cause a more drastic contrast than if the initial water content was relatively high. Because this is difficult to assess and has not been widely studied, the Freznel volume and the estimated volume of water needed to change a detectable volume of sample by $1.0 \%$ were used as a relatively accurate measure of detection (Bulford, 2002 and Piggot, 2004).

To assess the ability of GPR to monitor water content changes as a result of artificial infiltration, ZOP surveys were performed during water infiltration. The results shown in Figure 8 are expressed in terms of the change in water content $\left(\mathrm{m}^{3} / \mathrm{m}^{3}\right)$ with respect to the pre-infiltration profile. The only consistent water content increases that were observed in the refuse below the clay cap (below $0.6 \mathrm{~m}$ ) occurred at depths between $1 \mathrm{~m}$ and $2 \mathrm{~m}$. By the last day of the monitoring, the ZOP profiling indicates water content increased by $0.018 \mathrm{~m}^{3} / \mathrm{m}^{3}, 0.022 \mathrm{~m}^{3} / \mathrm{m}^{3}$ and $0.013 \mathrm{~m}^{3} / \mathrm{m}^{3}$ water at the depths of $1.3,1.5$ and $1.7 \mathrm{~m}$ respectively. These absolute differences, although small, are greater than the experimental uncertainty of $+/-0.01 \mathrm{~m}^{3} / \mathrm{m}^{3}$ determined by Parkin et al. (2000) for the ZOP method. To further confirm that changes in water content were a result of water infiltration, results show a relatively logical pattern of water increase from the beginning of the infiltration experiment to the end with a few minor exceptions. In addition, the area affected by the change appeared to increase and travel deeper into the BHs as water infiltration progressed. 
The water content decreases seen at 3.5 and $3.7 \mathrm{~m}$ appear to be isolated readings and may be the results of erroneous first arrival time picks. Variations below $5.3 \mathrm{~m}$ occur in a zone of consistent poor data quality and are not reliable. It should also be noted that the profiles for both June 7 and June 10 are systematically shifted to lower values, indicating a small systematic zero-time calibration problem.

\subsubsection{MOG Data}

MOG data collected pre- and post-water infiltration is used to complement the ZOP data collected during infiltration. Very minimal water content increases are visible in the MOG images as seen in Figure 9. This is as expected, considering the very small volume of water that entered the waste and the confirmatory results of the ZOP measurements. The increase in water content is visible in the upper portion of the scan, specifically between $1.2 \mathrm{~m}$ and $1.9 \mathrm{~m}$. These locations directly correspond to the locations of notable change discussed in the ZOP data (Section 4.3.2).

Overall, the MOG data confirms the results of the ZOP data. However this particular study is heavily reliant on data in the first $2 \mathrm{~m}$ of the study area. As discussed, MOG's detection ability at the upper portions of the study area are suspect and must be interpreted with caution because of low density ray coverage in the top, bottom and side portions of the survey area. Therefore MOG results cannot stand alone and must remain supplementary to ZOP data. Considering both ZOP and MOG data, results show sufficient amounts of evidence to be relatively certain that water content increases occurred and were detected by GPR. The MOG data also supports the ZOP data in that it does not indicate any water content increase at depth.

\subsection{Confirmation of Vertical Cross-Borehole GPR Approach}

Based on the success using borehole GPR at RWL, it was concluded that vertical cross-borehole GPR approach should be further tested at the GL to establish the reliability of the technique

\subsubsection{Data Quality}

Monitoring data quality during the study was accomplished by evaluating the repeatability of the data. To do so, every ZOP survey was taken in duplicate or triplicate. The correlation coefficient calculated for 
each ZOP pair was used to evaluate the duplicated data for variability between measurements (Table 4). It is clear that the repeatability is high and consistent between BHs 0 and 2. In addition, data quality was evaluated by calculating time shift between ZOP pairs (i.e., data sets), as seen in Table 4. The values given in Table 4 are the $y$-intercepts of the linear relationship between the first arrival times when first arrival times for each ZOP pair are plotted against each other. The low value of the $y$-intercepts indicate that there is no systematic shift between data sets.

\subsubsection{ZOP Data}

At the GL, the maximum distance at which the reliable quality $50 \mathrm{MHz}$ cross-borehole GPR could be acquired was approximately $2 \mathrm{~m}$. The $100 \mathrm{MHz}$ antennas were not effective at any separation distance. The acquired GPR results at GL were very similar to those acquired at the RWL. However, the quality of GL data was slightly lower than that of the RWL. This relative poorer signal quality could be the result of higher water content in the waste at GL. Overall, the decrease in signal strength was attributed to a decrease in signal to noise ratio, which occurred rapidly with an increase in $\mathrm{BH}$ separation at a greater rate than at the RWL.

Figure 10 compares GPR derived water content profile for the ZOP survey between BHs 0 and 2 (i.e., $\mathrm{BH}$ separation distance of approximately $2 \mathrm{~m}$ ) versus the laboratory derived water content profile taken at $\mathrm{BH}$ 0. These profiles slightly differ in vertical pattern of water content. However, the overall average water obtained by these two methods do compare favourable. The $50 \mathrm{MHz}$ ZOP data between BHs 0 and 2 indicate an average refuse water content over the entire profile length on July $30^{\text {th }}$ of $0.263 \mathrm{~m}^{3} / \mathrm{m}^{3}$. In comparison the laboratory derived water content was on average $0.321 \mathrm{~m}^{3} / \mathrm{m}^{3}$, giving an absolute difference of $0.058 \mathrm{~m}^{3} / \mathrm{m}^{3}$ or an $18.1 \%$ percent difference, relative to laboratory derived data. Again the relative closeness in water content values suggests that these values are comparable in the sense of "orders of magnitude" and supports the use of GPR to measure water content in-situ, providing important data for modeling calculations. Furthermore, the ZOP data indicates that overall, the landfill material at GL is wetter that at RWL as confirmed by the laboratory samples.

\subsubsection{MOG Data}


The overall poorer data quality at GL exacerbated the effects of transmitter-receiver separation distance on GPR signal quality noted above for the MOG survey geometry. An example of a MOG gather given in Figure 11, shows that the decrease in data quality greatly affected first arrival picking. As a consequence, processing the MOG data in GeoTom gave many outliers (Figure 12). Hence, the $50 \mathrm{MHz}$ MOG data collected between BHs 0 and 2 was processed using a $20 \%$ picking threshold and corrected using the $8.69 \%$ time shift previously calculated; the resulting image is seen in Figure 13.

The MOG results are similar at the RWL. MOG data cannot be directly compared to ZOP data because each ZOP measurement is representative of the average velocity between the BHs. However when an irregular water distribution pattern exists, MOG data reflects ZOP data. Patterns of increase and decrease in the ZOP data can be identified in the MOG data. This is especially noted at the extremes located at an approximate depth of $2 \mathrm{~m}, 3 \mathrm{~m}$ and $4.5 \mathrm{~m}$.

It is important to note that although similarities in water content data collected through MOG and ZOP methods do exist, two issues must be taken into account when interoperating the all MOG data. Firstly, when examining tomographic images for all data it appears that there are similarities between the tomographic image of water content and the general pattern of density of ray coverage in a typical MOG scan, Secondly, as discussed, due to the nature of the survey geometry inherent to the MOG borehole technique, issues concerning the effects of transmitter-receiver separation distance on GPR signal quality become more important. These issues are exacerbated at the extremes of transmitter-receiver separation distances. When examining all tomographic images generated, it is important to note that the data is strongly affected by the range of useful transmitter-receiver separations distances in a MOG scan, The patterns seen in the tomographic images could be an artifact of either or a combination of the above issues.

Considering the application of GPR as a tool to measure water content within a large scale landfill, ZOP measurement proved to be more than sufficient. The thoroughness of MOG data collection, only successful at separation distances of less than approximately $2 \mathrm{~m}$, appears to be extravagant in term of the use of the data and its collection from a large scale landfill. Decrease in data quality at the extremes of MOG surveys further proves that MOG data collection is an unsuitable application in a large-scale landfill setting and should only be used to compliment ZOP measurements. 


\subsection{Engineering Application}

Of the GPR methods investigated, cross-borehole GPR ZOP proved to be the most appropriate method to measure in-situ water content. The nature of cross-borehole GPR ZOP method will allow simple and efficient gathering of water content information at different locations within a landfill and at different landfills. At the same time the installation of access tubes will provide continual access for the antennas, allowing temporal data collection at the same location.

The ability to successfully gather water content both spatially and temporally will greatly benefit the prediction side of landfill behaviour and methane gas production. Predictive models need in situ water content, and since there is limited information on how to measure in situ water content in a landfill, modellers estimate in situ water content, hindering the accuracy in predictions. The completed research gives a tool to address this deficiency.

\subsection{SUMMARY}

Completion of the research has shown that surface GPR does not have the capability to effectively measure water content in a heterogeneous landfill environment. Vertical cross-borehole GPR has the capability to measure water content in a heterogeneous landfill. Of the two techniques tried in the borehole approach, ZOP and MOG, ZOP is a simpler and more efficient method to measure in situ water content within a large scale landfill.

Effectiveness of GPR, as separation distance increases, is a function of water content and landfill characteristics. The results showed that the effectiveness of GPR decreases with an increase in separation distance between BHs. Higher water content further decreases the effective separation distance. However there appears to be a corresponding increase in accuracy of the GPR measurements, but this cannot be identified as primarily due to water content. For a separation distance of $2 \mathrm{~m}$ at the two landfills, the difference in GPR and lab measured water contents were reasonable at 33.9\% (drier landfill) and 18.1\% (wetter landfill). Both these values show success in using GPR ZOP in the cross-borehole approach, but confirm the need for further research to determine the precise impact of water content on GPR measurements. 
The results of the water infiltration experiment showed that GPR was successful in measuring small increases in water content in a heterogeneous landfill environment. However, additional field testing is required at a site with better permeability to more fully examine the ability of the GPR ZOP technique to monitor temporal changes in the water content profile due to infiltration through landfill material as well to examine preferential flow pathways and possibly a wetting front.

Additionally, the procedure used to analyze the GPR data introduces two sources of systematic error that requires further investigation. One is the inherent time delay of the first arrival time pick, which increases the water content value of the waste being analyzed. First arrival times were automatically picked by the software (PICKER) using a $5 \%$ picking threshold. Picking threshold is expressed as a percent of the maximum amplitude of the trace in the designated picking Time Window. A $5 \%$ picking threshold level is generally accepted as a suitable level. However, a $5 \%$ threshold first arrival times that are slightly later than actual first breaks. The consequence is that a later first break pick will give a higher water content value when compared to actual field values. This suggests that further study is needed on calculating a scale factor that can be applied to GPR measured water content values.

A second source of systematic error in the permittivity - water content relationship described by the Topp et al. (1987) equation. The determination of water content from GPR data is entirely reliant upon this relationship. Based on the results of this study, Topp's equation continually under predicts water content values measured in landfilled solid waste, suggesting a required updating of the relationship specific to solid waste. Further research into incorporating Li and Zeiss (2001) findings concerning permittivity - water content relationships is recommended.

\subsection{ACKNOWLEDGEMENTS}

This research was supported by a NSERC Strategic Grant. Supporting partners were the Region of Waterloo and City of Hamilton. Special thanks are extended to David McCaughan, Supervisor, Environmental Systems, Region of Waterloo and Fabiano Gondim, Supervisor of Landfills of City of Hamilton for their support in conducting the research and allowing access to the sites. The authors would also like to thank Prof. Gary Parkin, School of Environmental Science, University of Guelph for the use of his GPR equipment in this study. 


\subsection{REFERENCES}

Annan, A.P. (2007) Chapter 11 Ground-Penetrating Radar, in Near-Surface Geophysics, D. K. Butler (ed..), Society of Exploration Geophysicists, Tulsa OK, 357-438.

Atcha, S.Y. and Van Son, V.T. (2002) Opportunities with Landfill Gas. Sustainable Enterprise Program \& Economics Program: World Resources Institute, Corporate Guide to Green Power Markets. Installment 2.

Balsdon, J. (2008) Annual Report: Glanbrook Landfill Site for City of Hamilton, Jagger Hims LTD.

Bevan, M., Endres, A., Rudolph, D. and Parkin, G. (2003) The non-invasive characterization of pumpinginduced dewatering using ground penetrating radar. Journal of Hydrology, 281:55-69.

Bulford, L.B. (2002) Characterization of Water Infiltration through a Municipal Solid Waste Landfill Cover Vegetated with and without Young Hybrid Poplar Trees. Masters thesis, University of Guelph, Guelph, Ontario, Canada.

Cassiani, G., Fusi, N., Susanni, D. and Deiana, D. (2008) Vertical radar profiling for the assessment of landfill capping effectiveness. Near Surface Geophysics, 6:133-142.

Chan C.Y. and Knight R.J. (1999) Determining water content from dielectric measurements in layered materials. Water Resources Research, 35: 85-93.

Chang, N., and Davila, E. (2008) Municipal solid waste characterization and management strategies for the Lower Rio Grande Valley, Texas. Waste Management, 28:776-794.

De laco, R., Green, A. and Horstmeyer, H. (2000) An Integrated Geophysical Study of a Landfill and its Host Sediments. European Journal of Environmental and Engineering Geophysics, 4:223-263.

Deignan, T. (1991) Low and High Frequency Electromagnetics in Landfill Investigations. Symposium on the Application of Geophysics to Engineering and Environmental Problems SAGEEP, March 11-14: 361-372

Environment Canada. (2002) The Science and Environment Bulletin: Harnessing the Power of Landfill Gas.

Faust, M. (2004) A three-dimensional ground-penetrating radar study at the Norman landfill, Norman, OK. Masters thesis, University of Oklahoma, Norman, Oklahoma. 203p.

Garg, A., Achari, G., and Joshi, R. (2006) A model to estimate the methane generation rate constant in sanitary landfills using fuzzy synthetic evaluation. Waste Management and Research, 24:363-375.

Garg, A., Achari, G., and Joshi, R. (2007) Application of Fuzzy Logic to Estimate Flow of Methane for Energy Generation at a Sanitary Landfill. Journal of Energy Engineering. 133(4):212-223.

Gilson, E., Pilon, J., Redman, D., Annan, P., and Leggatt D. (1996) Development of pulseEKKO borehole radar; in Current Research 1996-D; Geological Survey of Canada, 125-131.

Glancy, T. (2009) Characterization of Solid Waste in a Bioreactor Landfill Using Seismic Borehole Techniques. M.A.Sc. thesis, Department of Civil and Environmental Engineering, Carleton University, May.

Guyonnet, D., Gourry, J.C., Bertrand, L. and Amraoui, N. (2003) Heterogeneity detection in an experimental clay liner. Canadian Geotechnical Journal, 40(1):129-160. 
Hussiman, J., Hubbard, S., Redman, J., and Annan, P. (2003) Measuring Soil Water Content with Ground Penetrating Radar: A Review, Vadose Zone Journal, 2:476-491.

Imhoff, P.T., Reinhart, D.R., Englund, M., Guerin, R., Gawande, R., Han, B., Jonnalagadda, S., Townsend, T.G. and Yazdani, R. (2007) Review of state of the art methods for measuring water in landfills. Waste Management, 27:729-745.

Innovative Waste Consulting Services (2007) Landfill Operations Training Manual, Solid Waste Association of North America, Gainesville, Florida.

Klute, A. (1986) Methods of Soil Analysis: Part 1 Physical and Mineralogical Methods Second Edition. American Society of Agronomy, Inc. and Soil Science Society of America Inc. Wisconsin.

Knight, R. (2001) Ground Penetrating Radar for Environmental Applications. Annu. Rev. Earth Planet. Sci, 29:229-255.

Lanz, E., Maurer, H., Boerner, D., Horstmeyer, H., Green, A. (1998) Composite landfill characterization; an integrated geophysical study. Proceedings of SAGEEP, March 1998:437-444.

Li, R.S. and Zeiss, C. (2001) In situ Moisture content Measurements in MSW Landfills with TDR, Environmental Engineering Science, 18: 53-66.

Masbruch, K. and Ferre, T.P.A. (2003) A time domain transsion method for determining the dependence of the dielectric permittivity on volumetric water content: an application to municipal landfills, Vadose Zone Journal, 2:186-192.

McBean, E.A., Rovers, F.A., and Farquhar, G.J. (1995) Solid waste landfill engineering and design. Prentice-Hall. Toronto

Nuzman, C.E. and Kinn, C. (1995) The Search for Water goes Beyond Institution: Geophysical Surface Techniques verify Plentiful Aquifers. International Groundwater Technology, 1(9):23-30.

Parkin, G., Redman, D., von Bertoldi, P. and Zhang, Z. (2000) Measurement of soil water content below a wastewater trench using ground-penetrating radar. Water Resources Research, 36(8):2147-2154.

Piggott, S. (2004) Moisture Content Monitoring of Water Infiltration Experiments in a Landfill Cover using Horizontal Cross Borehole Ground Penetrating Radar. Environmental Geophysics Facility Department of Earth Science: University of Waterloo.

Porsani, J., Filho, W., Elis, V., Shimeles, F., Dourado, J., and Moura, H. (2004) The use of GPR and VES in delineating a contamination plume in a landfill site: a case study in SE Brazil. Journal of Applied Geophysics, 55:199-209.

Reddy, K. R., Hettiarachchi, H., Parakalla, N.S., and Gangathulasi, J. (2009) Geotechnical properties of fresh municipal solid waste at Orchard Hills Landfill, USA. Waste Management, 29, 952-959.

Region of Waterloo. (2007) Waterloo Landfill Site 2007 Progress Report. Region of Waterloo. 1-39.

Roth K., Schulin R., Fluhler H. and Attinger W. (1990) Calibration of time domain reflectometry for water content measurement using a composite dielectric approach. Water Resources Research, 26: 22672273.

Sensors and Software. (2001) EKKO-for-DVL pulseEKKO 100: User's Guide Version 1.0, Technical Manual 30. Sensors and Software Inc. 66p. 
Sensors and Software. (2008) 3-Day Short Course. Sensors and Software Inc. Attended by April Yochim. July 9-11.

Smith, R. (1999) Integrated geophysical investigation helps improve a landfill closure design. Proceedings of SAGEEP, March 1999:189-195.

Splajt, T., Ferrier, G., Frostick, L. (2003) Application of Ground Penetrating Radar in Mapping and Monitoring Landfill Sites. Environmental Geology, 44:963 967.

Staub, M.J., Laurent, J.P., Gourc, J.P. and Morra, C. (2010) Applicability of time domain reflectometry water content measurements in municipal solid waste, Vadose Zone Journal, 9:160-171

Tchobanoglous, G., Theisen H., and Vivil S. (1993) Integrated Solid Waste Management: Engineering Principles and Management Issues. McGraw-Hill Inc. New York. Chp 11.

Topp, G.C., Davis, J.L. and Annan, A.P. (1980) Electromagnetic Determination of Soil Water content: Measurements in Coaxial Transmission Lines. Water Resources Research, 16(3)574-583.

Tweeton, D.R. (2008) GeoTom, LLC Tomographic software for civil engineering applications. http://www.geotom.net.

USEPA. (1996) Turning a liability into a $\mathrm{n}$ asset: A landfill gas to energy project development handbook. USEPA Landfill Methane Outreach Program. EPA 430-B-96-0004. September 1996.

USEPA. (2006) Methane. United States Environmental Protection Agency. http://www.epa.gov/methane/sources.html

USEPA. (2008) Landfill Methane Outreach Program (LMOP). http://www.epa.gov/lmop/benefits.htm.

Wang, C.K., Garg, A., Achari, G. and Zytner, R.G. (2010) A Preliminary 2-D Gas Model for Sanitary Landfills Equipped with a Gas Extraction Well, 11th International Environmental Speciality Conference, CSCE 2010, Winnipeg, MB, June 9-12, 10p.

Zhao, L. (2007) Three-dimensional soil vapour extraction modeling, Ph.D., thesis, School of Engineering, University of Guelph. 


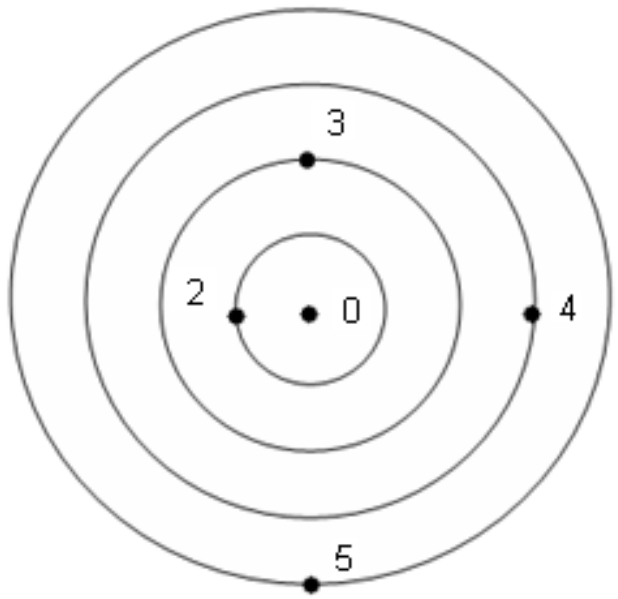

Figure 1: Layout of GPR Access Tubes 


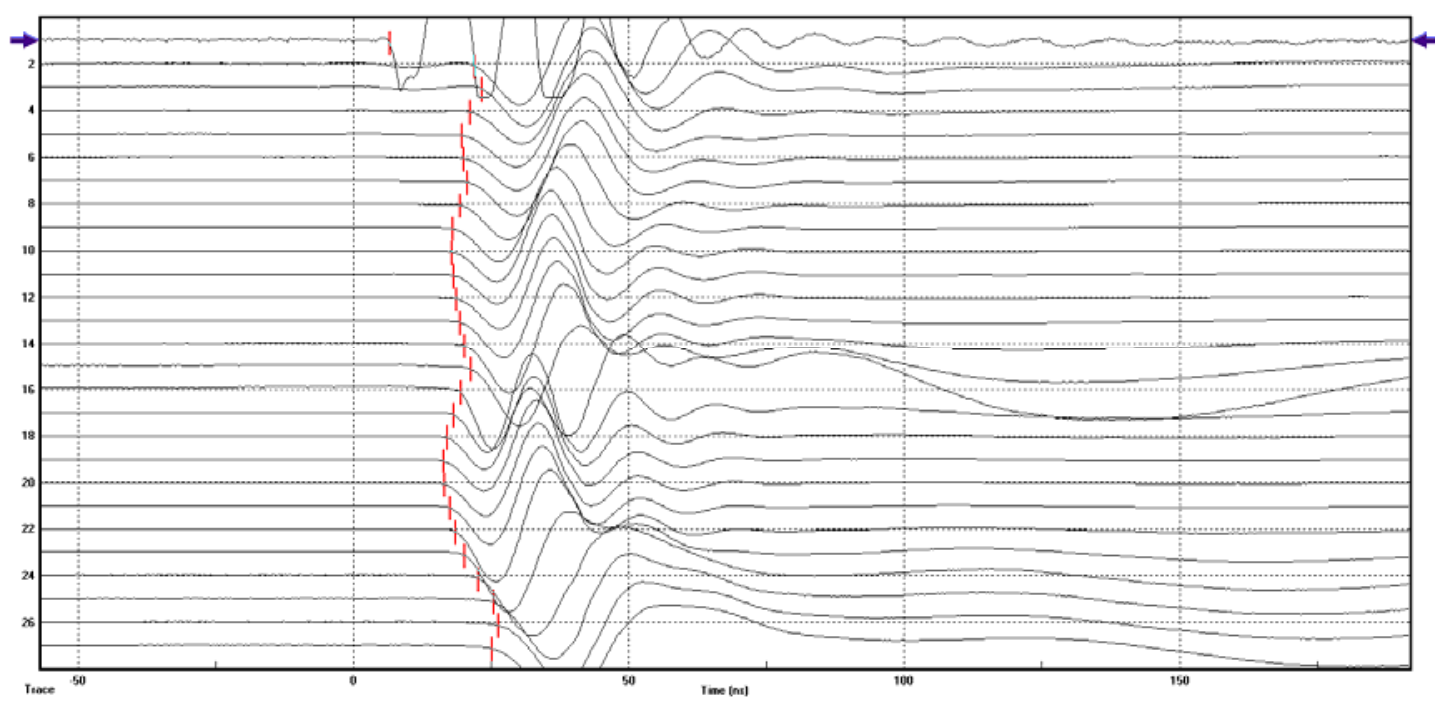

2(a) raw ZOP data at a separation distance of $2.16 \mathrm{~m}$

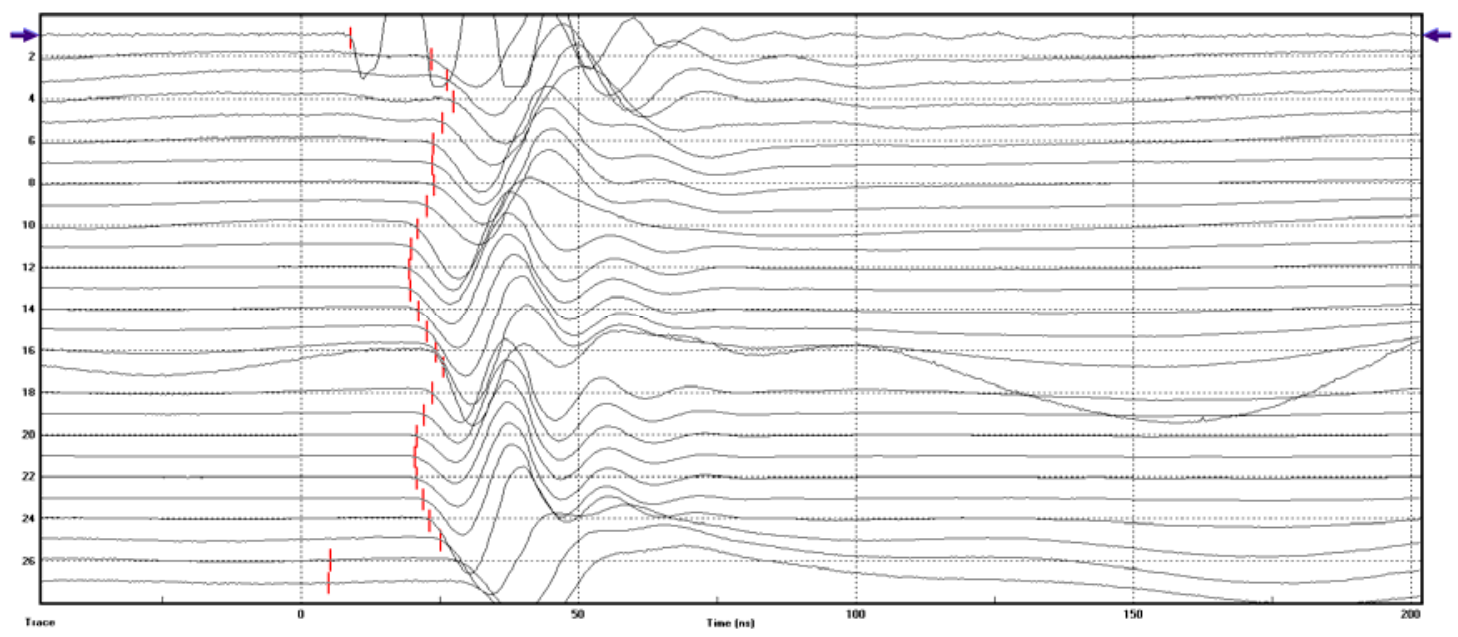

2(b) raw ZOP data at a Separation distance of $2.98 \mathrm{~m}$ 

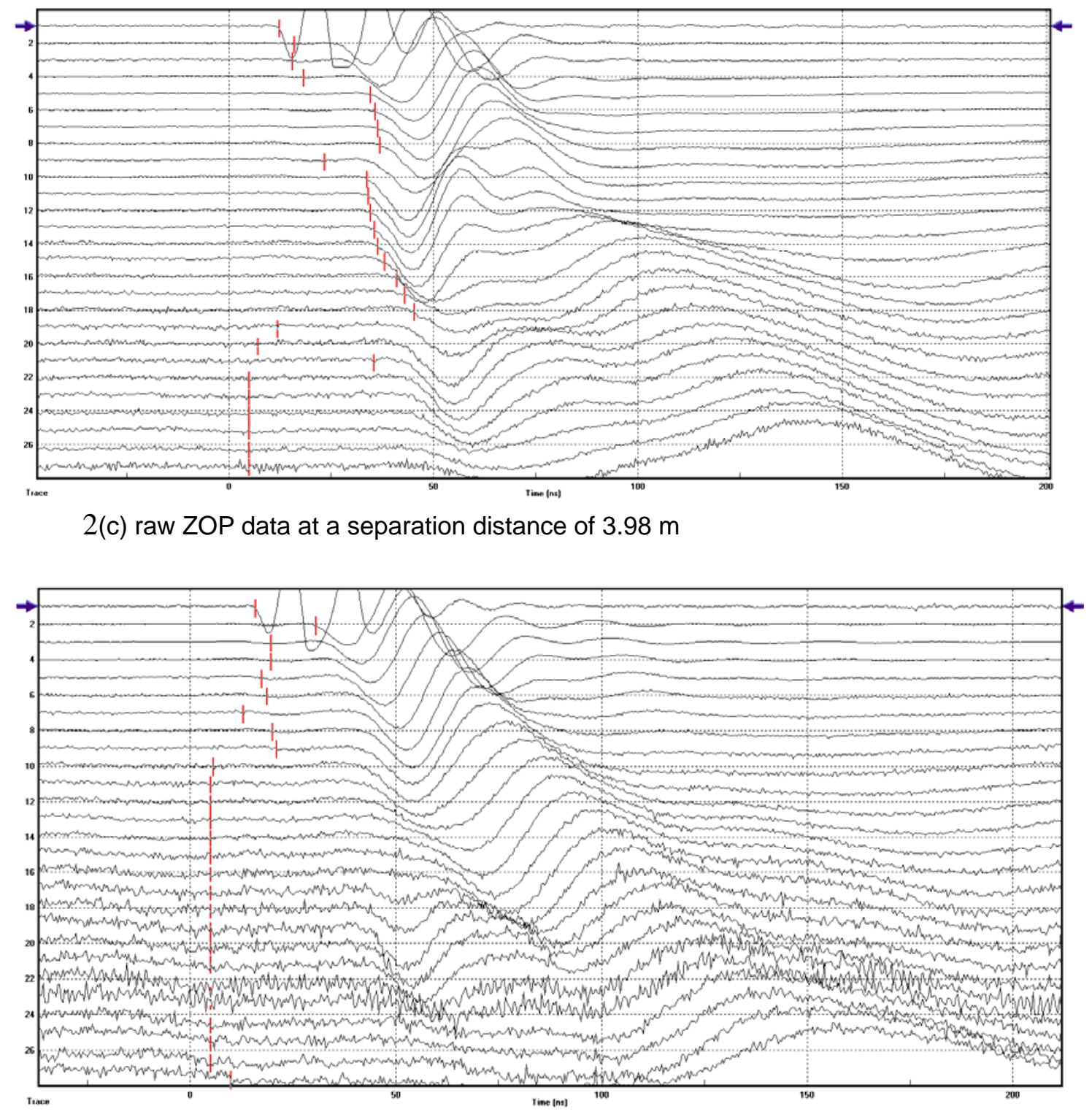

2(d) raw ZOP data at a separation distance of $4.93 \mathrm{~m}$

Figure 2: (a) and (b) ZOP $50 \mathrm{MHz}$ cross-borehole GPR on June 4, $20095 \%$ picking threshold; (c) and (d) ZOP 50 MHz cross-borehole GPR on June 4, $20095 \%$ picking threshold 


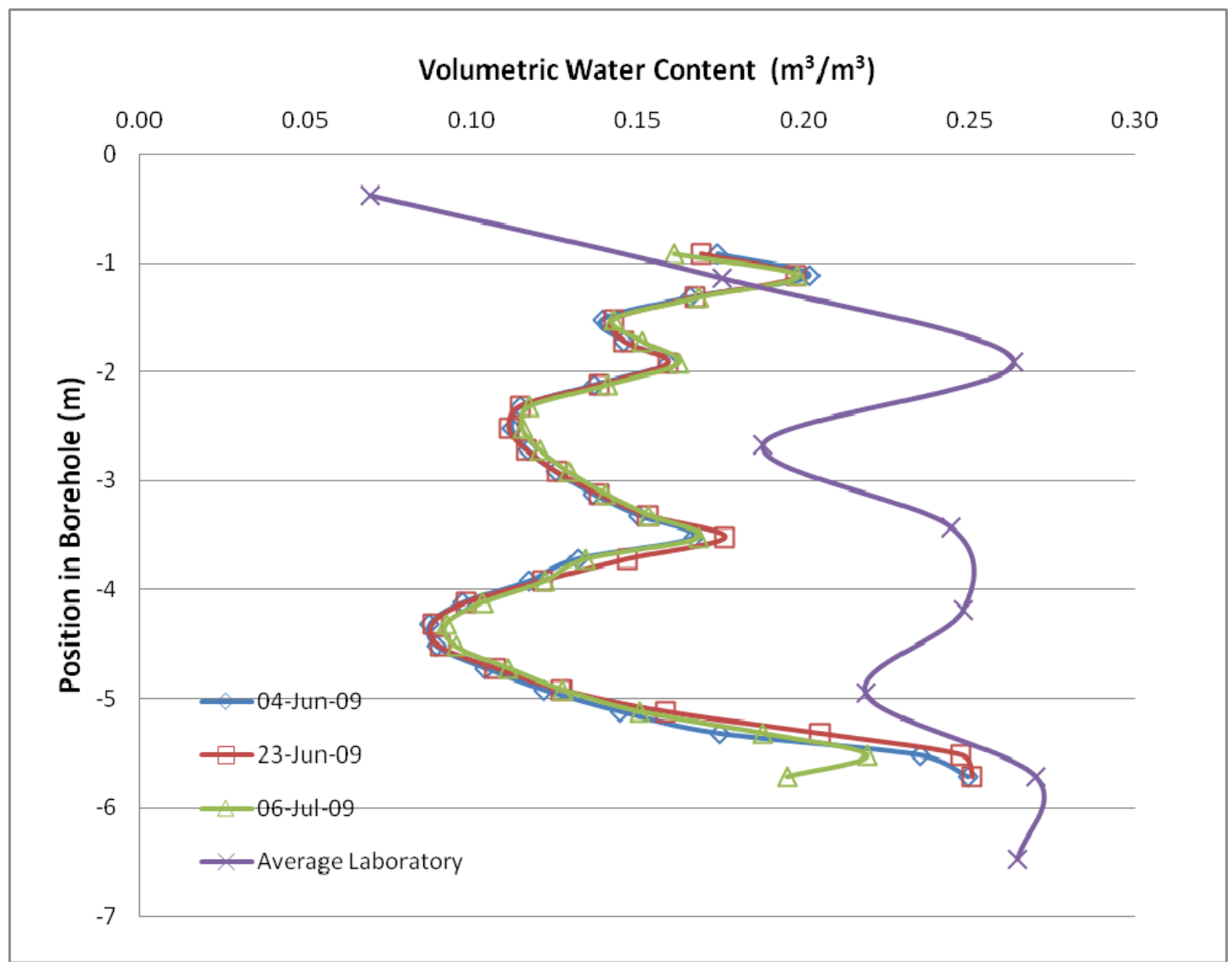

Figure 3: 50 MHz BH0-2 Pre-infiltration VS Average Laboratory Water Content 


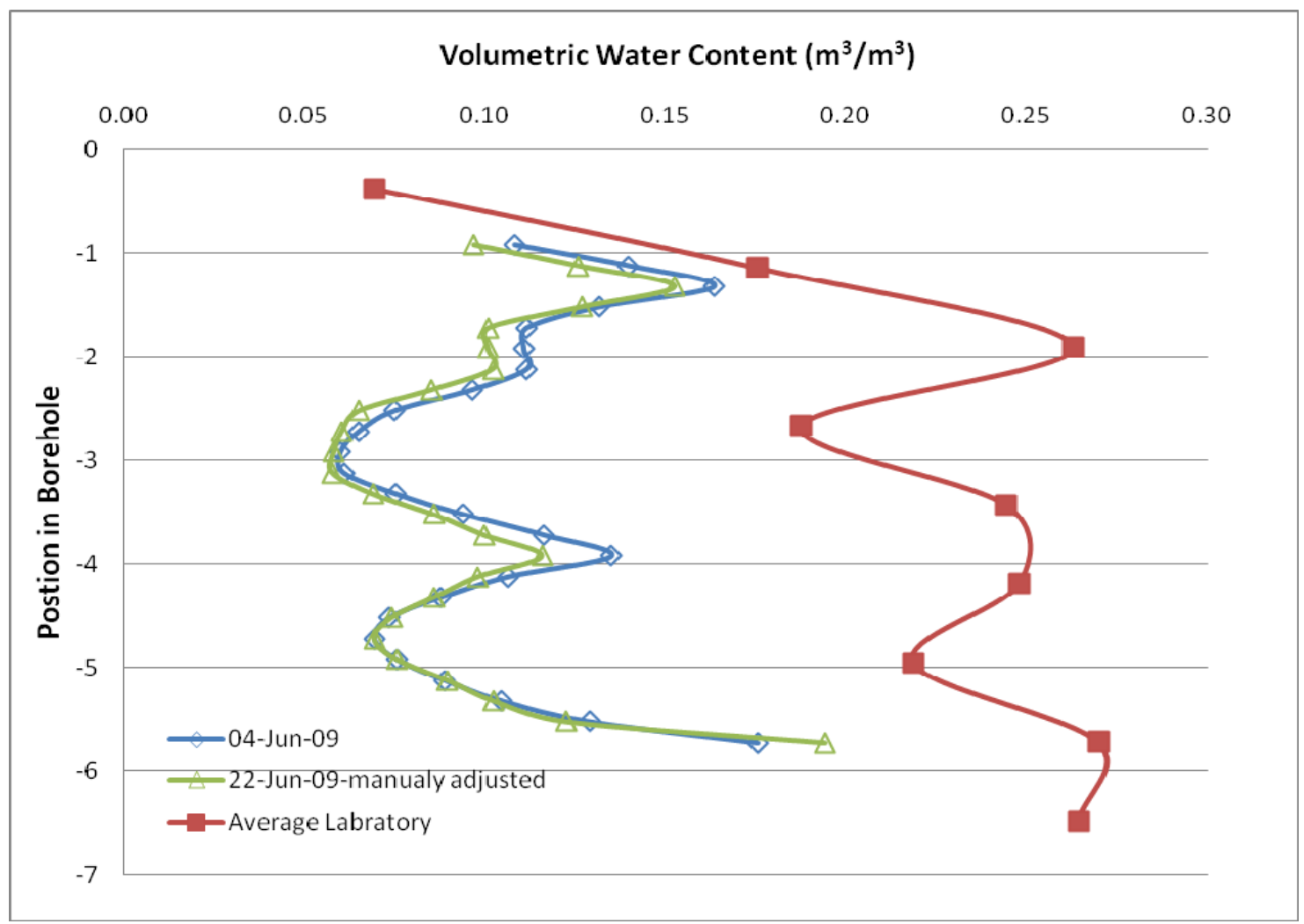

Figure 4: 50 MHz BH0-3 Pre-infiltration VS Average Laboratory Water Content 


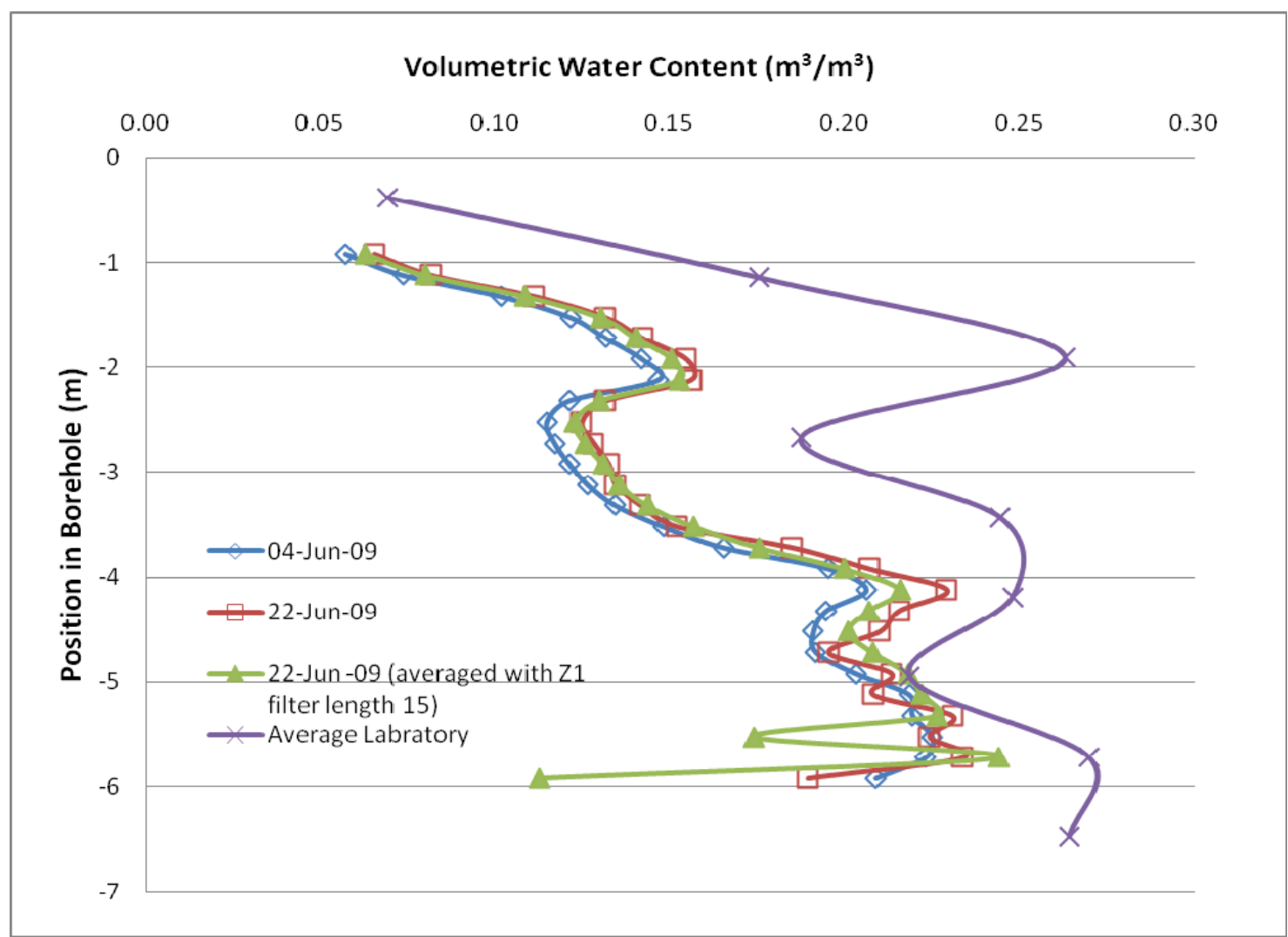

Figure 5: $50 \mathrm{MHz}$ BH0-4 Pre-infiltration VS Average Laboratory Water Content 


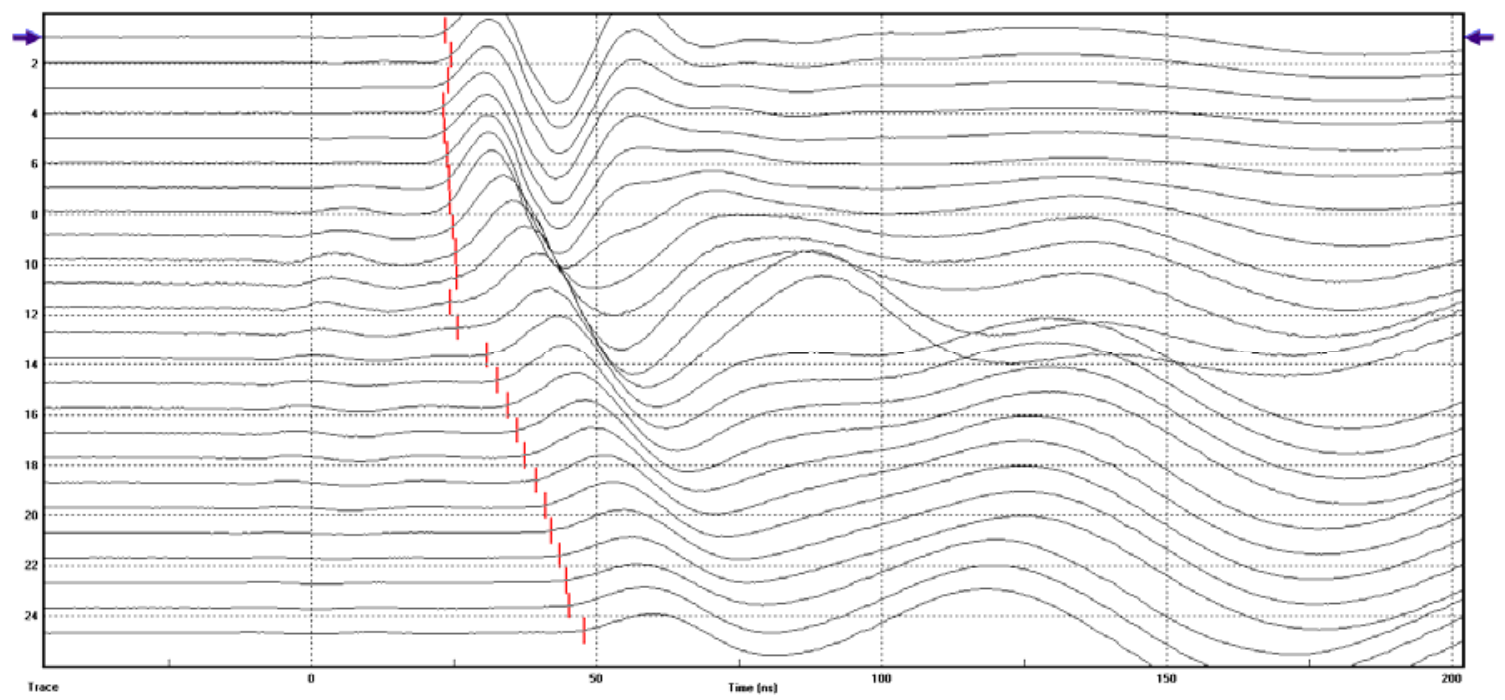

6(a) raw MOG data at a separation distance of $2.16 \mathrm{~m}$

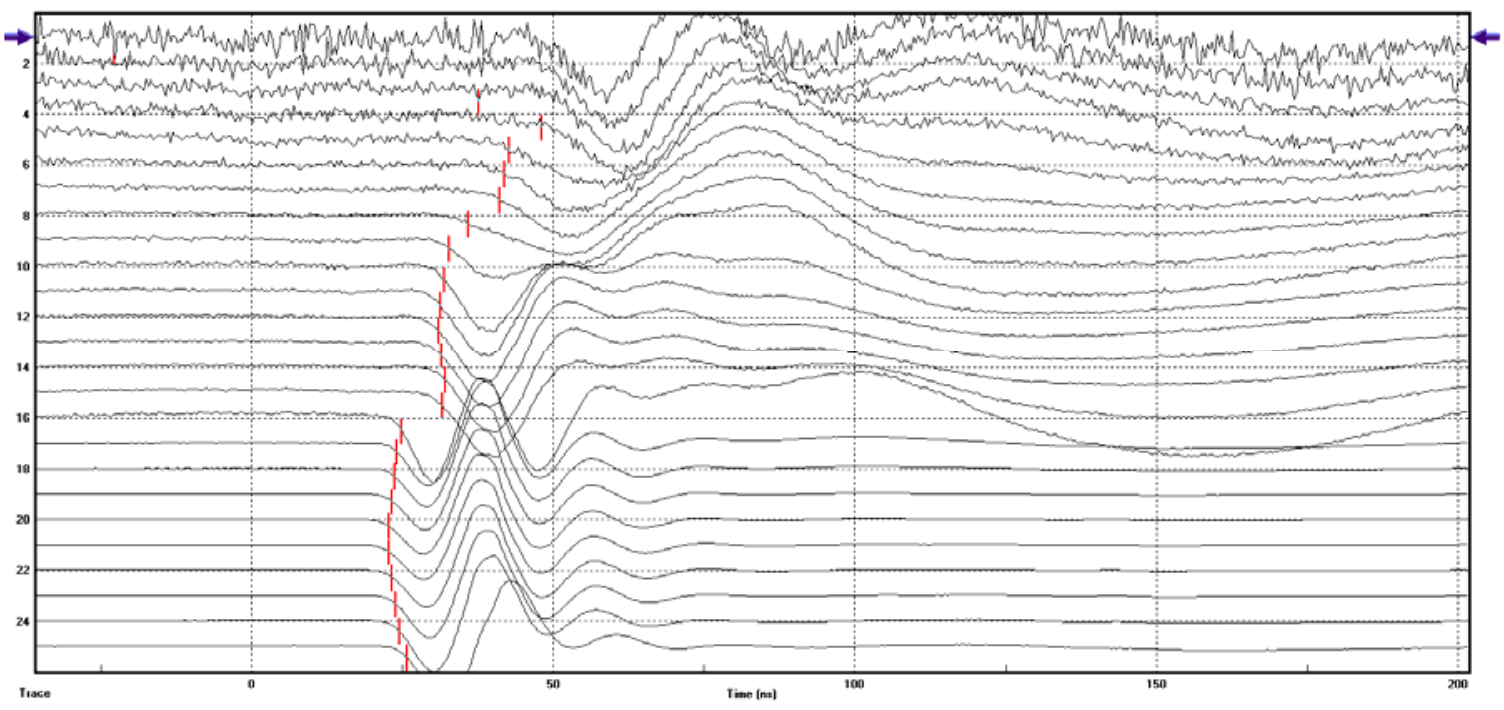

6(b) raw MOG data at a separation distance of $2.87 \mathrm{~m}$ 


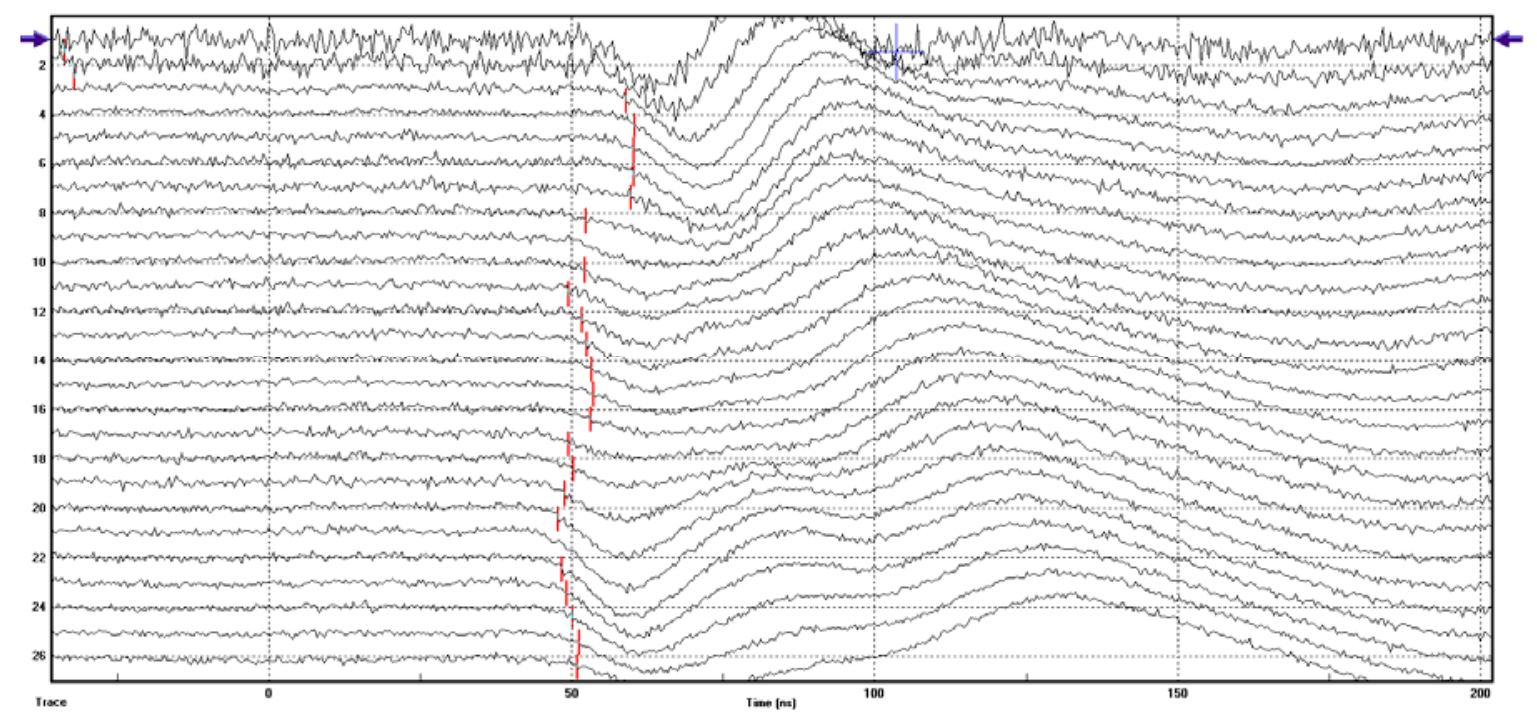

6(c) raw MOG data at a separation distance of $3.92 \mathrm{~m}$

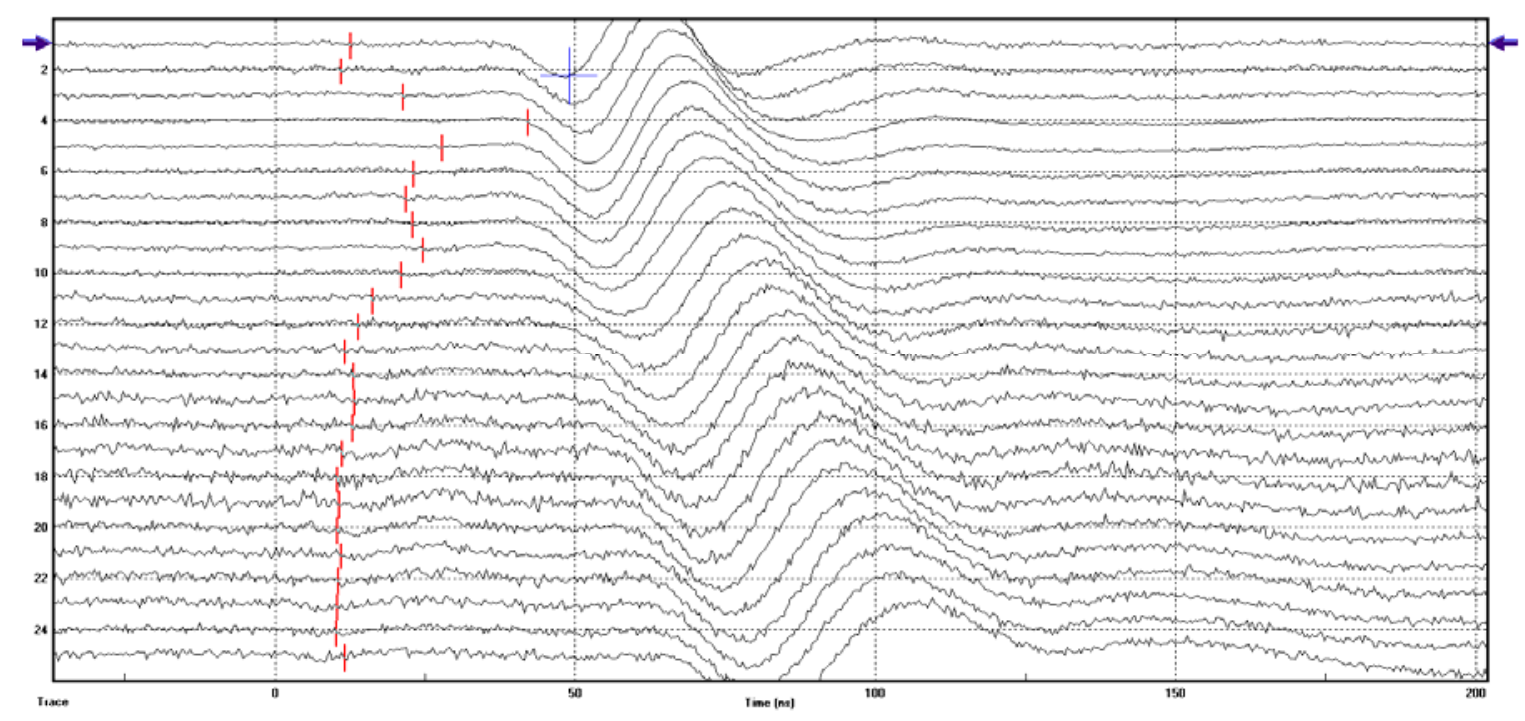

6(d) raw MOG data at a separation distance of $4.93 \mathrm{~m}$

Figure 6: (a) MOG $50 \mathrm{MHz}$ cross-borehole GPR on June 18th $200920 \%$ picking threshold, (b) MOG 50 MHz cross-borehole GPR on June 22nd $200920 \%$ picking threshold, (c) MOG 50 MHz cross-borehole GPR on June 22nd $200920 \%$ picking threshold, and (d) MOG 50 MHz crossborehole GPR on June 23nd $200920 \%$ picking threshold. 


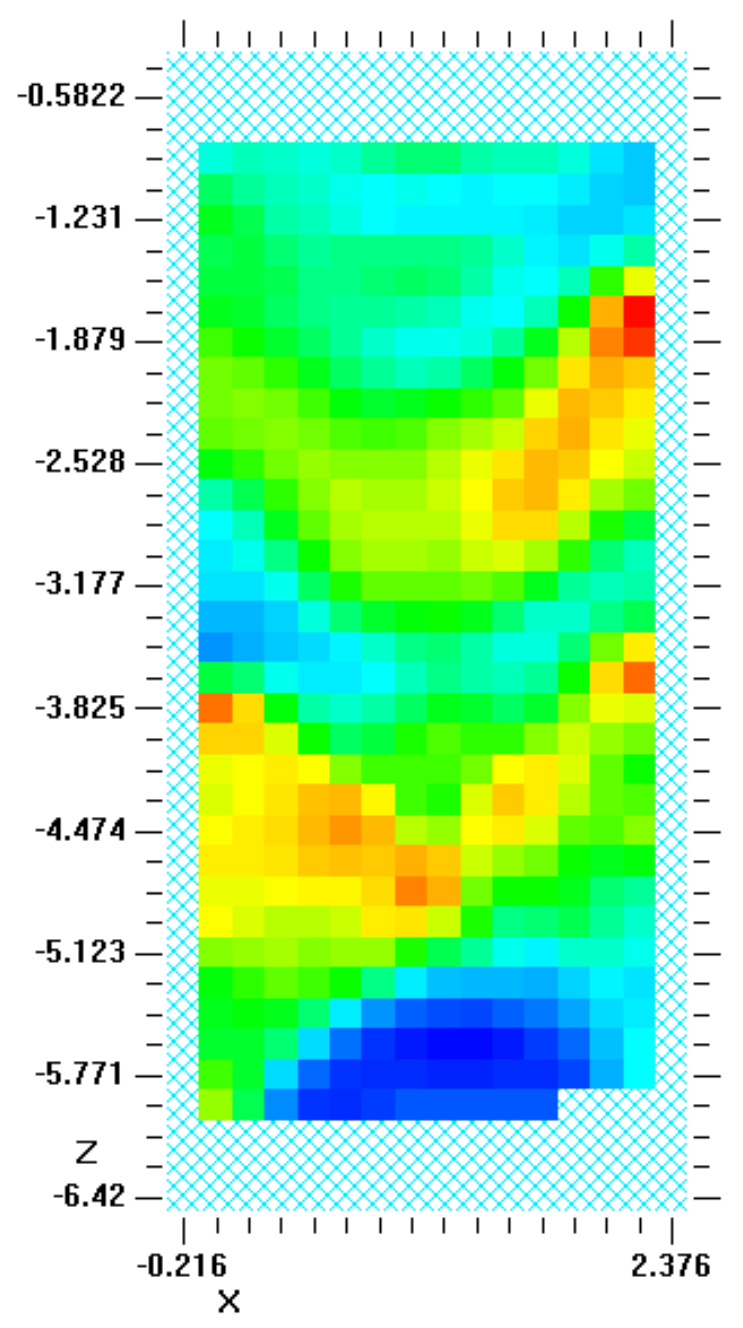

Water Content $\left(\mathrm{m}^{3} / \mathrm{m}^{3}\right)$

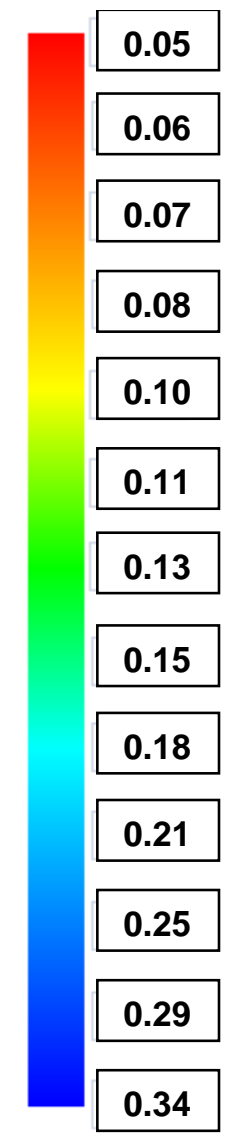

Figure 7: $50 \mathrm{MHz}$ MOG tomography of volumetric water content between $\mathrm{BH} 0$ and 2 on June 18th 2009 


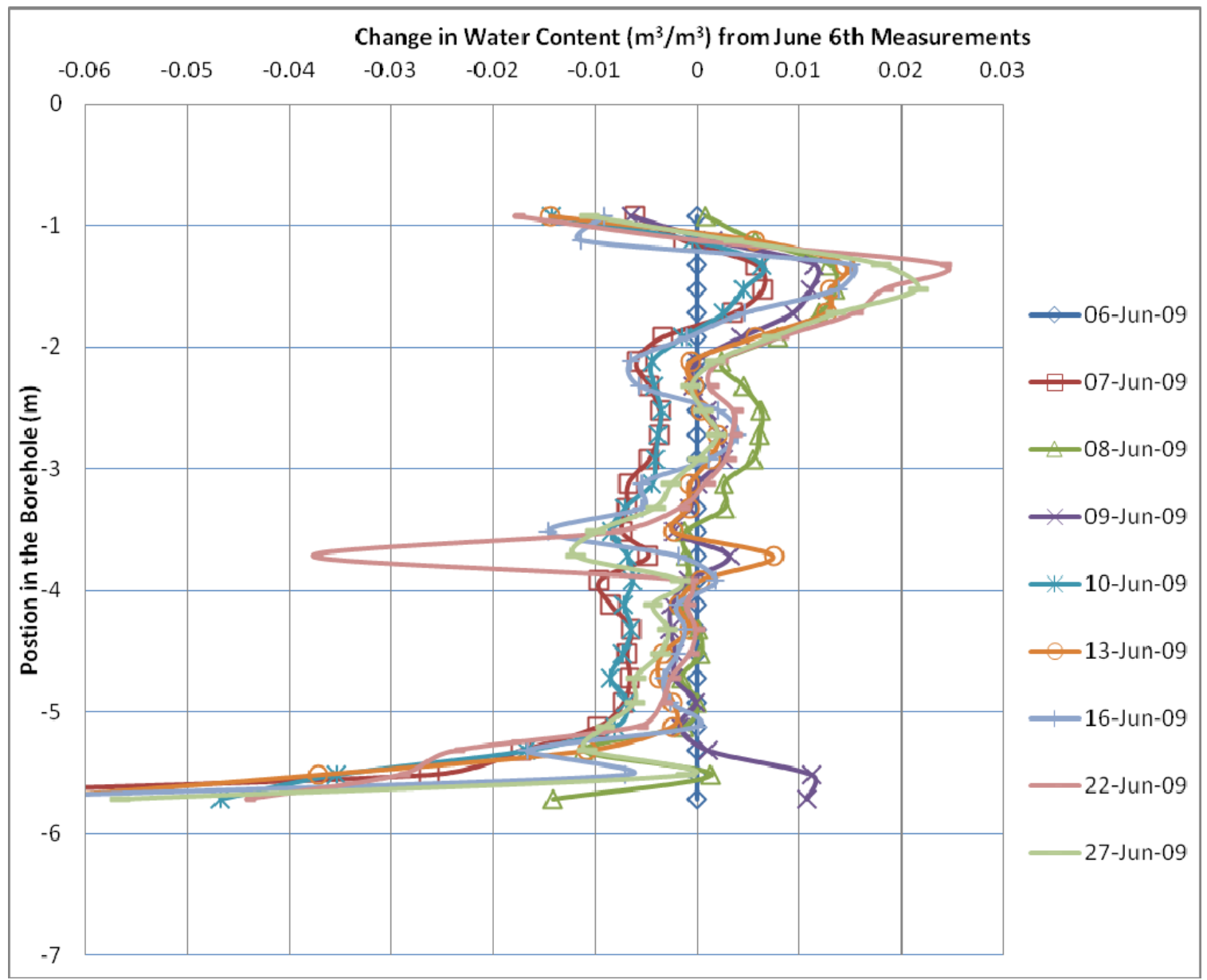

Figure 8: Change in Water Content during Infiltration RWL 


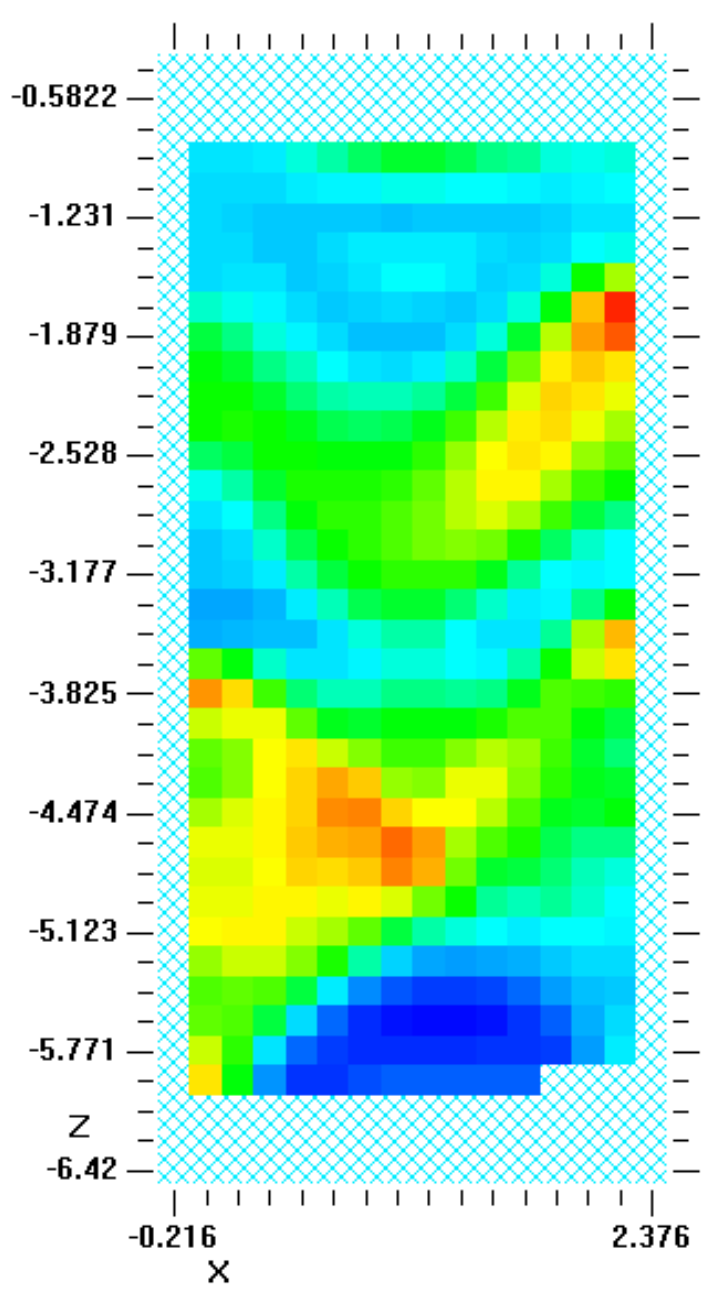

9(a) June 18th (pre-water infiltration)

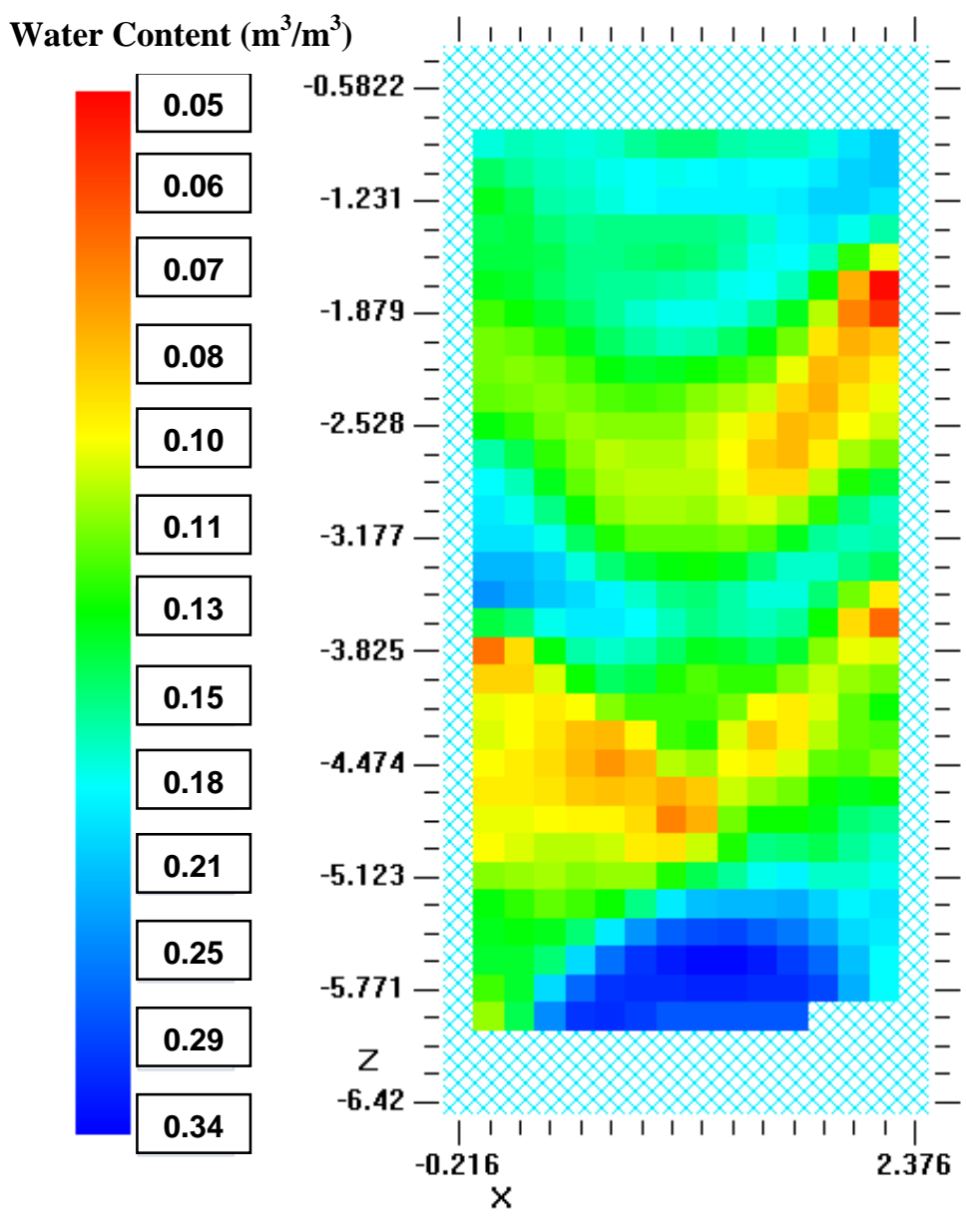

Water Content $\left(\mathrm{m}^{3} / \mathrm{m}^{3}\right)$

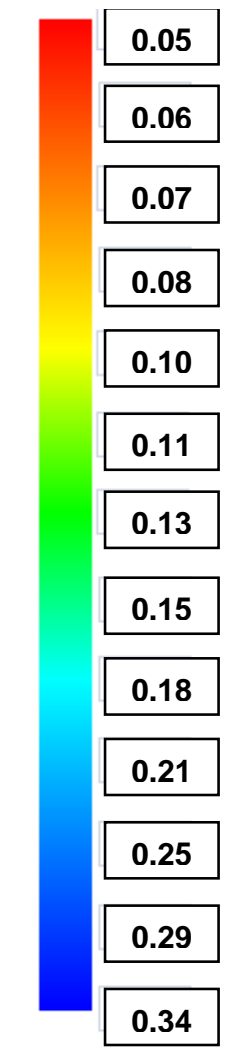

9(b) June $27^{\text {th }}$ (post-water infiltration)

Figure 9: $50 \mathrm{MHz}$ MOG tomography of volumetric water content between borehole 0 and 2 


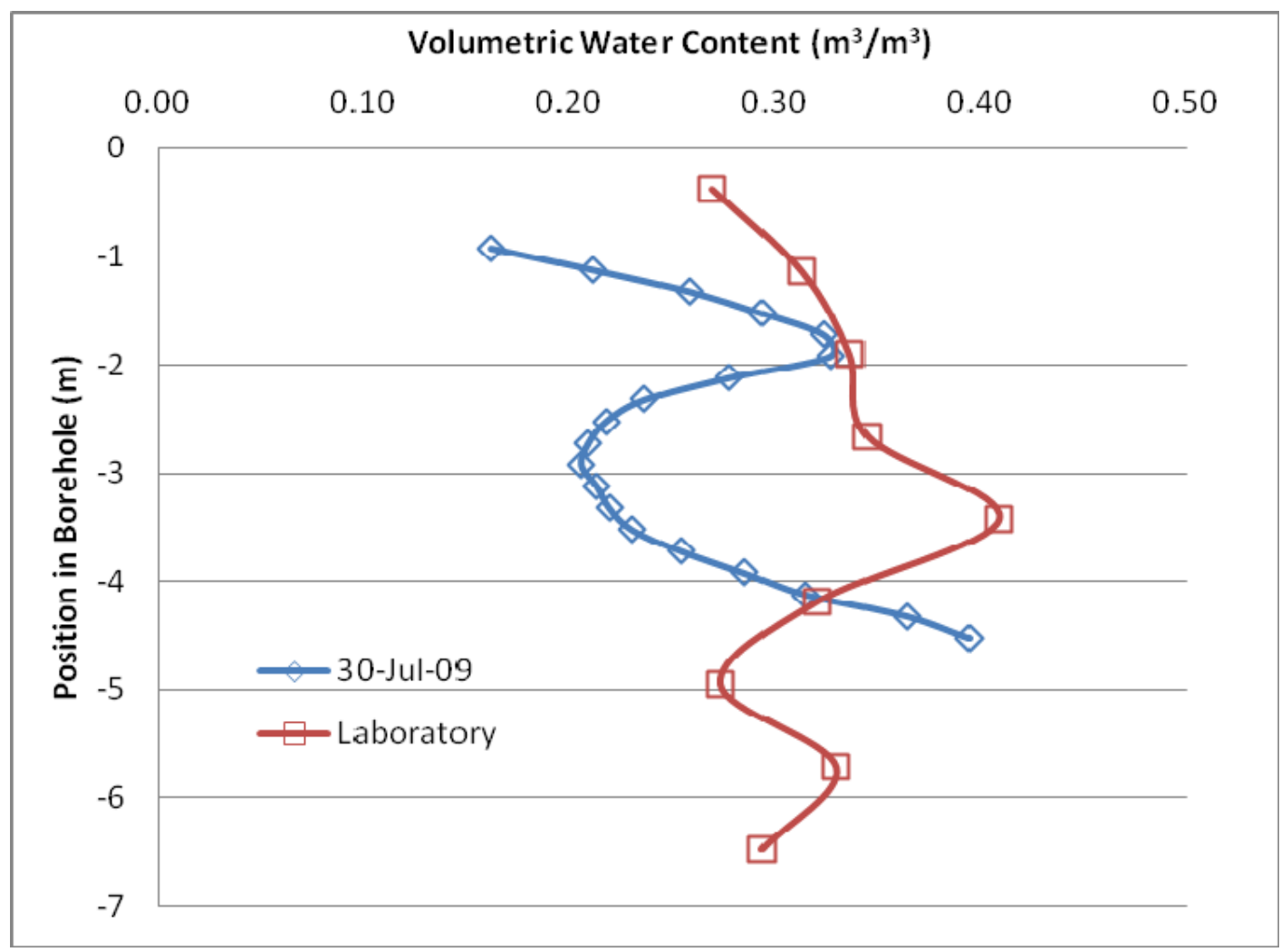

Figure 10: 50 MHz ZOP BH 0 - 2 VS Laboratory Water Content 


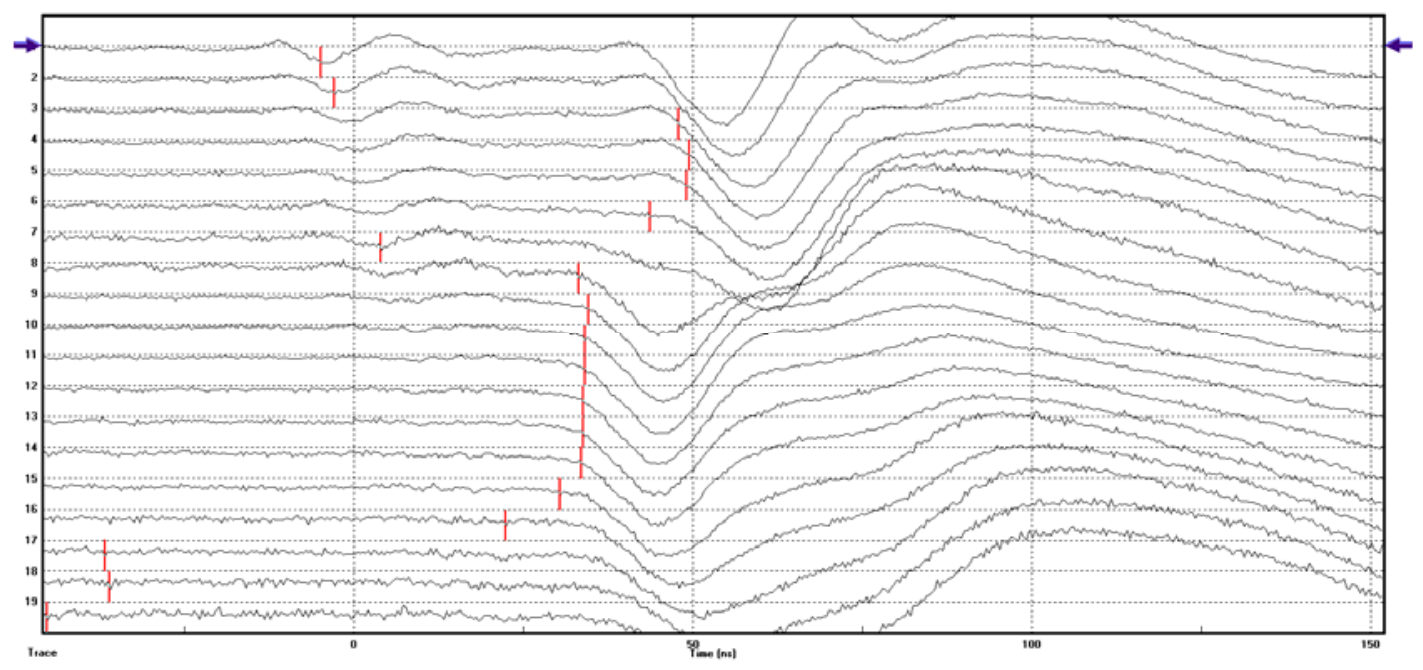

Figure 11: raw MOG data; 50 MHz MOG19 BH 0 to 2, 20\% picking threshold 


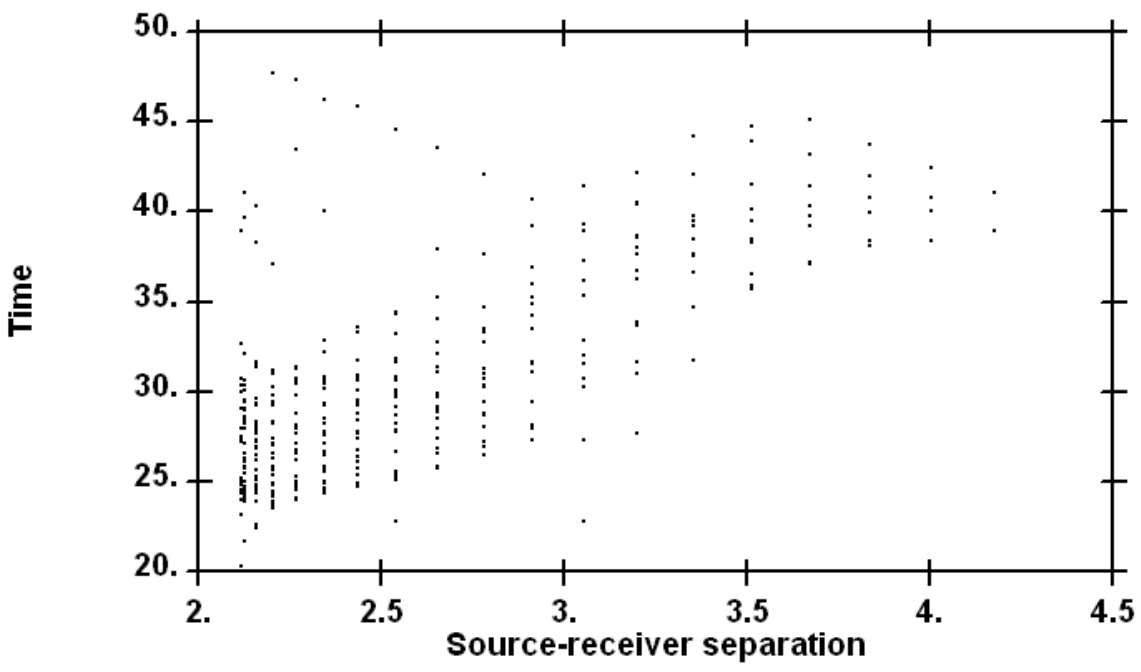

Figure 12: Outliers in $50 \mathrm{MHz}$ MOG at GL 


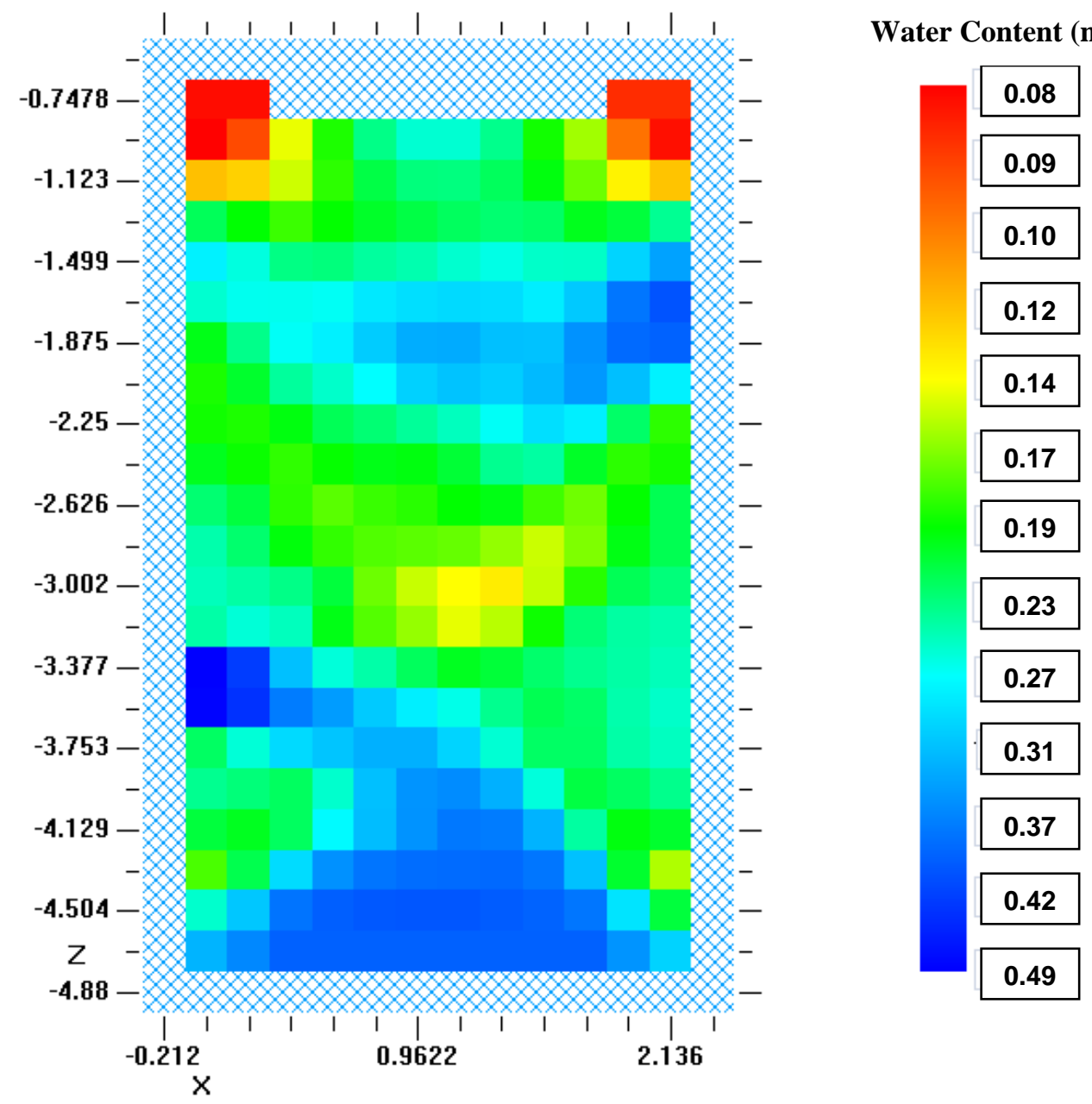

Figure 13: $50 \mathrm{MHz}$ MOG tomography of volumetric water content between borehole 0 and 2 on July 30th 2009 
Table 1: Correlation coefficients for duplicated $50 \mathrm{MHz}$ ZOP surveys pre-water infiltration RWL

\begin{tabular}{|c|c|c|c|c|}
\hline Date & $\begin{array}{c}\text { ZOP } \\
\text { Number }\end{array}$ & $\begin{array}{c}\text { Auto Picking } \\
\text { Notes }\end{array}$ & $\begin{array}{l}\text { Correlation } \\
\text { Coefficient }\end{array}$ & $\begin{array}{l}\text { Shift Between } \\
\text { Data Sets (ns) }\end{array}$ \\
\hline \multicolumn{5}{|c|}{ Borehole 0 to 2} \\
\hline 04-Jun-09 & $\mathrm{Z1}-\mathrm{Z2}$ & $5 \%$ & 0.99 & 0.03 \\
\hline 04-Jun-09 & $\mathrm{Z2}-\mathrm{Z3}$ & $5 \%$ & 0.82 & -0.13 \\
\hline 04-Jun-09 & $\mathrm{Z1}-\mathrm{Z3}$ & $5 \%$ & 0.81 & -0.07 \\
\hline 23-Jun-09 & $\mathrm{Z1}-\mathrm{Z2}$ & $5 \%$ & 1.00 & -0.13 \\
\hline 06-Jul-09 & $\mathrm{Z} 1-\mathrm{Z2}$ & $5 \%$ & 0.99 & -0.06 \\
\hline 06-Jul-09 & $\mathrm{Z2}-\mathrm{Z3}$ & $5 \%$ & 0.99 & -0.13 \\
\hline 06-Jul-09 & $\mathrm{Z1}-\mathrm{Z3}$ & $5 \%$ & 0.98 & -0.17 \\
\hline \multicolumn{5}{|c|}{ Borehole 0 to 3} \\
\hline 04-Jun-09 & Z1- Z2 & $5 \%$ & 1.00 & -0.34 \\
\hline 04-Jun-09 & $\mathrm{Z1}-\mathrm{Z3}$ & $5 \%$ & $0.99 *$ & -0.12 \\
\hline 04-Jun-09 & $\mathrm{Z2}-\mathrm{Z3}$ & $5 \%$ & $0.98^{*}$ & 0.29 \\
\hline 22-Jun-09 & $\mathrm{Z1}-\mathrm{Z2}$ & $\begin{array}{l}5 \% \text { - hand } \\
\text { picked }\end{array}$ & $0.99 * *$ & 0.05 \\
\hline \multicolumn{5}{|c|}{ Borehole 0 to 4} \\
\hline 04-Jun-09 & $\mathrm{Z1}-\mathrm{Z2}$ & $20 \%$ & $1.00^{* * *}$ & 0.28 \\
\hline 04-Jun-09 & $\mathrm{Z2}-\mathrm{Z3}$ & $20 \%$ & $1.00^{* * *}$ & -0.06 \\
\hline 04-Jun-09 & $\mathrm{Z1}-\mathrm{Z3}$ & $20 \%$ & $1.00 * * *$ & 0.18 \\
\hline 22-Jun-09 & $Z 1-Z 2$ & $20 \%$ & $-0.30 * * * *$ & 0.05 \\
\hline
\end{tabular}

Note: For shift between data set calculation data set values plotted on the on the $x$ and $y$ axis are in the order in which they appear (i.e. Z1 -Z2 corresponds to Z1 plotted on X axis and Z2 plotted on $Y$ axis

*Last picks of Z2 and Z3 were removed because they were meaningless

**Last picks were removed because Z1 last pick was meaningless

*** Last two picks were removed because they were meaningless

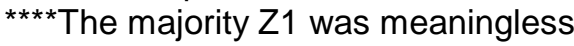


Table 2: Comparison of laboratory derived versus GPR derived water content at RWL

\begin{tabular}{|c|c|c|c|c|c|}
\hline \multicolumn{2}{|c|}{ Laboratory Data } & \multicolumn{2}{|c|}{ GPR Data } & \multirow{2}{*}{$\begin{array}{c}\% \\
\text { Difference }\end{array}$} & \multirow{2}{*}{$\begin{array}{l}\text { Absolute Difference } \\
\qquad\left(\mathrm{m}^{3} / \mathrm{m}^{3}\right)\end{array}$} \\
\hline Borehole & $\begin{array}{l}\text { Average Water } \\
\text { Content }\left(\mathrm{m}^{3} / \mathrm{m}^{3}\right)\end{array}$ & Borehole separation & $\begin{array}{l}\text { Average Water } \\
\text { Content }\left(\mathrm{m}^{3} / \mathrm{m}^{3}\right)\end{array}$ & & \\
\hline 0 & 0.222 & Borehole 0-2 & 0.145 & $34.4 \%$ & 0.0770 \\
\hline 3 & 0.204 & Borehole 0-3 & 0.0996 & $51.1 \%$ & 0.1044 \\
\hline 5 & 0.234 & Borehole 0-4 & 0.162 & $30.9 \%$ & 0.0720 \\
\hline \multicolumn{2}{|c|}{$\begin{array}{c}\text { Average Laboratory Water } \\
\text { Content }\left(\mathrm{m}^{3} / \mathrm{m}^{3}\right)\end{array}$} & Borehole separation & $\begin{array}{l}\text { Average Water } \\
\text { Content }\left(\mathrm{m}^{3} / \mathrm{m}^{3}\right)\end{array}$ & $\begin{array}{c}\% \\
\text { Difference }\end{array}$ & $\begin{array}{l}\text { Absolute Difference } \\
\qquad\left(\mathrm{m}^{3} / \mathrm{m}^{3}\right)\end{array}$ \\
\hline & \multirow{3}{*}{0.220} & Borehole 0-2 & 0.145 & $33.9 \%$ & 0.0750 \\
\hline & & Borehole 0-3 & 0.0996 & $54.7 \%$ & 0.1204 \\
\hline & & Borehole 0-4 & 0.162 & $26.3 \%$ & 0.0580 \\
\hline
\end{tabular}


Table 3: Correlation coefficients for duplicated ZOP surveys post-water infiltration

\begin{tabular}{|c|c|c|c|c|}
\hline Date & $\begin{array}{c}\text { ZOP } \\
\text { Number }\end{array}$ & $\begin{array}{c}\text { Auto Picking } \\
\text { Notes }\end{array}$ & $\begin{array}{c}\text { Correlation } \\
\text { Coefficient }\end{array}$ & $\begin{array}{c}\text { Shift Between } \\
\text { Data Sets (ns) }\end{array}$ \\
\hline \multicolumn{5}{|c|}{ Borehole 0 to 2} \\
\hline 07-July-09 & Z1 - Z2 & $5 \%$ & 1.00 & -0.08 \\
\hline 08-July-09 & Z1 - Z2 & $5 \%$ & 1.00 & 0.04 \\
\hline 09-July-09 & Z1 - Z2 & $5 \%$ & 0.99 & -0.16 \\
\hline 10-July-09 & Z1 - Z2 & $5 \%$ & 0.95 & $0.01^{* *}$ \\
\hline 13-July-09 & Z1 - Z2 & $5 \%$ & 0.82 & $-0.05^{*}$ \\
\hline 16-July-09 & Z1 - Z2 & $5 \%$ & $0.99 *$ & $0.21^{*}$ \\
\hline 22-July-09 & Z1 - Z2 & $5 \%$ & 0.98 & 0.21 \\
\hline 27-July-09 & Z1 - Z2 & $5 \%$ & 0.97 & -0.002 \\
\hline
\end{tabular}

Note: For shift between data set calculation data set values plotted on the on the $x$ and $y$ axis are in the order in which they appear (i.e. Z1 -Z2 corresponds to Z1 plotted on X axis and Z2 plotted on $Y$ axis

*Last 4 picks are removed because they were all meaningless early picks in Z1

** Last 2 picks are removed because outliers 
Table 4: Correlation coefficients for duplicated ZOP surveys at GL

\begin{tabular}{|c|c|c|c|c|}
\hline Date & $\begin{array}{c}\text { ZOP } \\
\text { Number }\end{array}$ & Auto Picking Notes & $\begin{array}{c}\text { Correlation } \\
\text { Coefficient }\end{array}$ & $\begin{array}{c}\text { Shift Between } \\
\text { Data Sets (ns) }\end{array}$ \\
\hline \multicolumn{5}{|c|}{ Borehole 0 to 2 } \\
04-Jun-09 & Z1 - Z2 & $\begin{array}{c}5 \% \text { - approximately bottom 5 traces } \\
\text { manually adjusted }\end{array}$ & 0.99 & $0.03^{*}$ \\
\hline 04-Jun-09 & Z1 - Z3 & $\begin{array}{c}5 \% \text { - approximately bottom 5 traces } \\
\text { manually adjusted }\end{array}$ & 0.99 & $0.70^{*}$ \\
\hline 04-Jun-09 & Z2 - Z3 & $\begin{array}{c}5 \% \text { - approximately bottom 5 traces } \\
\text { manually adjusted }\end{array}$ & 0.98 & $0.77^{*}$ \\
\hline
\end{tabular}

Note: For shift between data set calculation data set values plotted on the on the $x$ and $y$ axis are in the order in which they appear (i.e. Z1 -Z2 corresponds to Z1 plotted on X axis and Z2 plotted on $Y$ axis

*Last 2 picks are removed because outliers 